\title{
Continuous motor sequence learning: cortical efficiency gains accompanied by striatal functional reorganization.
}

Citation for published version (APA):

Reithler, J., van Mier, H. I., \& Goebel, R. (2010). Continuous motor sequence learning: cortical efficiency gains accompanied by striatal functional reorganization. Neuroimage, 52(1), 263-276. https://doi.org/10.1016/j.neuroimage.2010.03.073

Document status and date:

Published: 01/08/2010

DOI:

10.1016/j.neuroimage.2010.03.073

Document Version:

Publisher's PDF, also known as Version of record

Document license:

Taverne

Please check the document version of this publication:

- A submitted manuscript is the version of the article upon submission and before peer-review. There can be important differences between the submitted version and the official published version of record.

People interested in the research are advised to contact the author for the final version of the publication, or visit the DOI to the publisher's website.

- The final author version and the galley proof are versions of the publication after peer review.

- The final published version features the final layout of the paper including the volume, issue and page numbers.

Link to publication

\footnotetext{
General rights rights.

- You may freely distribute the URL identifying the publication in the public portal. please follow below link for the End User Agreement:

www.umlib.nl/taverne-license

Take down policy

If you believe that this document breaches copyright please contact us at:

repository@maastrichtuniversity.nl

providing details and we will investigate your claim.
}

Copyright and moral rights for the publications made accessible in the public portal are retained by the authors and/or other copyright owners and it is a condition of accessing publications that users recognise and abide by the legal requirements associated with these

- Users may download and print one copy of any publication from the public portal for the purpose of private study or research.

- You may not further distribute the material or use it for any profit-making activity or commercial gain

If the publication is distributed under the terms of Article 25fa of the Dutch Copyright Act, indicated by the "Taverne" license above, 


\title{
Continuous motor sequence learning: Cortical efficiency gains accompanied by striatal functional reorganization
}

\author{
Joel Reithler*, Hanneke I. van Mier, Rainer Goebel \\ Cognitive Neuroscience Department, Faculty of Psychology and Neuroscience, Maastricht University, The Netherlands \\ Maastricht Brain Imaging Center (M-BIC), Maastricht University, The Netherlands
}

\section{A R T I C L E I N F O}

\section{Article history:}

Received 15 March 2010

Accepted 25 March 2010

Available online 1 April 2010

\section{Keywords:}

Extended learning

fMRI

Functional reorganization

Nonvisual

Skill acquisition

\begin{abstract}
A B S T R A C T
The acquisition and generation of action sequences constitute essential elements of purposeful human behavior. However, there is still considerable debate on how experience-driven changes related to skill learning are expressed at the neural systems level. The current functional magnetic resonance imaging (fMRI) study focused on changes in the neural representation of continuous movement sequences as learning evolved. Behavioral and neural manifestations of nonvisual motor practice were studied both within the time frame of a single scanning session, as well as after several days of extended practice. Based on detailed behavioral recordings which enabled the continuous characterization of the ongoing learning process at the single subject level, sequence-specific decreases in activation throughout a learning-related network of cortical areas were identified. Furthermore, the spatial layout of this cortical network remained largely unchanged after extensive practice, although further decreases in activation levels could be observed as learning progressed. In contrast, the posterior part of the left putamen showed increased activation levels when an extensively trained sequence needed to be recalled. Overall, these findings imply that continuous motor sequence learning is mainly associated with more efficient processing in a network of consistently recruited cortical areas, together with co-occurring activation pattern changes at the subcortical level.
\end{abstract}

(C) 2010 Elsevier Inc. All rights reserved.

\section{Introduction}

The ability to generate intentional action sequences enables us to freely interact with the world that surrounds us and is therefore crucial with respect to many aspects of our daily lives (Tanji, 2001). Neuroimaging techniques have been successfully applied to localize brain regions involved in the production of willed actions, and have uncovered highly distributed networks of cortical and subcortical areas that conjointly underlie the emergence of purposeful behavior (e.g., Culham et al., 2006). In addition, it has become increasingly clear over the last decades that these underlying neural representations are not static constructs, but inherently hold the potential to dynamically adapt to new situations and altered requirements throughout life (Pascual-Leone et al., 2005). As this neural plasticity can not only be observed during the recovery from injury, but can also be induced by behavioral training, additional efforts have been directed towards exploring the dynamics within the identified neural networks associated with learning (Poldrack, 2000). However, experiments on learning-related plasticity in the motor domain have frequently led to inconsistent results, both with respect

\footnotetext{
* Corresponding author. Cognitive Neuroscience Department, Faculty of Psychology and Neuroscience, Maastricht University, Universiteitssingel 40, PO Box 616, 6200 MD, Maastricht, The Netherlands. Fax: +31 433884125.

E-mail address: j.reithler@maastrichtuniversity.nl (J. Reithler).
}

to the implicated regions and the direction of the observed changes (Toni et al., 1998; van Mier, 2000), rendering the consistent classification of resulting changes in brain activation patterns a challenging enterprise (Kelly and Garavan, 2005). In order to gain more insights into practice-related plasticity at the neural systems level, the present fMRI study focused on continuous movement patterns resembling the smooth succession of coherent motion elements in handwriting. Subjects were instructed to learn a set of 2-dimensional continuous movement sequences by tracing along predefined maze trajectories, while keeping their eyes closed throughout the entire experiment (van Mier et al., 1993). Since no visual information on the desired trajectory was provided, subjects had to solely rely on somatosensory and proprioceptive feedback while performing the required movements. While excluding any effects of visual guidance and therefore concentrating on the motor aspects of the task at hand, the performed tracing task is also complementary to the commonly studied Serial Reaction Time (SRT)like paradigms (Nissen and Bullemer, 1987) in two respects. Foremost, each response is specifically coupled to a presented sensory event in such SRT type of sequence learning tasks. This inherent 'associative' component potentially blurs what is actually being learned (Keele et al., 2003; but see Bischoff-Grethe et al., 2004). In addition, there is a strong bias in the motor sequence literature towards the use of discrete button-press tasks (Sanes, 2003; Clegg et al., 1998), which raises the question whether the observed effects also 
generalize to situations in which a different type of movement sequencing is required.

Furthermore, only a limited number of studies has investigated extended practice conditions (Doyon et al., 2003). Therefore, we aimed to track the behavioral and neural manifestations of learning by including two scanning sessions, separated by 3 days of additional practice. The main goal was to investigate how increases in proficiency are reflected at the neural systems level during skill acquisition. And more specifically, whether the observed changes in brain activation patterns in the chosen time window would be more strongly characterized by increases in local processing efficiency (i.e., probably reflected by decreases in the extent or level of activation) or dynamic functional reorganizations (i.e., changes in the spatial layout of the involved network; see Poldrack, 2000; Kelly and Garavan, 2005). In order to answer these questions, the different learning phases were individually defined based on the gathered detailed behavioral recordings to form a continuous representation of the ongoing learning process. Whereas a subset of the acquired data was already briefly discussed in a different context elsewhere (Reithler et al., 2007), the dedicated report presented here focuses on the studied practice-induced neuroplasticity, and provides a detailed account on the revealed changes in behavioral performance and the associated activation patterns due to learning.

The current findings will be discussed in the light of recent models describing the dynamic cerebral changes that are thought to occur during the different stages of skill acquisition (Doyon and Ungerleider, 2002; Doyon and Benali, 2005; Ashe et al., 2006; Doyon et al., 2009).

\section{Materials and methods}

\section{Participants}

Twelve healthy subjects ( 6 males; mean age $=25$ years, standard deviation $=1.4$ years) participated in the current study. All subjects were right-handed as determined by the Edinburgh Handedness Inventory (Oldfield, 1971; mean score $=94$, standard deviation $=9$ ) and gave written informed consent according to a protocol approved by the local research ethics committee.

\section{Experimental paradigm}

\section{Motor learning task}

Subjects were asked to learn a set of new movement sequences by continuously tracing along different predefined maze trajectories. Although each maze had a unique geometry, all mazes shared certain characteristics: the groove to which the pen movements were restricted was $6 \mathrm{~mm}$ wide and $3 \mathrm{~mm}$ deep, consisted of eight straight segments that were connected by right-angled corners and formed a path with a total length of $260 \mathrm{~mm}$. At each corner, a so-called 'dead-end' was included to enforce a choice with regard to the direction in which to proceed. Additionally, the maze path always constituted a closed loop and could therefore be traced continuously during a given period of time. The different maze trajectories are depicted in Fig. 1 as part of an overview on the study's design described in more detail below.

Subjects were instructed to trace the maze path as fast and as accurately as possible, while keeping their eyes closed throughout the whole experiment. Only the dominant right hand was used and the tracing movements had to be performed in a clockwise fashion. The instructions also stressed that subjects should make an effort to learn the executed movement patterns, in order to be able to reproduce the established motor routines later on without having to rely on the maze's groove to guide them.

Since becoming more proficient at executing the required movement sequences inherently led to an increase in motor output (i.e., velocity) over time, two additional control conditions were included to distinguish purely performance-related changes in brain activity from true learning-related effects (van Mier et al., 1998). Both control conditions consisted of tracing a square trajectory, which all subjects were familiar with because it was shortly traced during the adjustment of the setup prior to scanning (see below). In the control conditions, the square trajectory should either be traced as fast as possible ('SQfast'), or at a velocity matching the slow tracing at the early stages of learning ('SQslow'), assuming that no additional sequence-specific learning would occur.

Both the subjects' head and arms were stabilized by foam padding to minimize task-related motion. The necessary tracing movements were mainly performed using the joint of the wrist. The mazes were fixated in a specifically designed holder, which was placed on a custom-built table that covered the subject's abdomen. Before starting the experiment, the position of the table was adjusted in such a way that the required movements could be performed rather effortlessly. A resistance-based MR-compatible recording method was used to register the pen tracing movements while scanning (Reithler et al., 2006).

\section{Order and structure of experiments}

All twelve subjects participated in a series of experiments. During the first scanning session (scheduled on Monday), they had to learn two new movement sequences by continuously tracing one of two mazes in trials of $30 \mathrm{~s}$. The active tracing trials were alternated with rest periods (lasting for $20 \mathrm{~s}$ ) in which the pen should be kept at a fixed starting position, to which the subject's hand was re-positioned at the end of each tracing trial by the experimenter. The start and end of each tracing trial were indicated by a short high $(1000 \mathrm{~Hz})$ and low $(500 \mathrm{~Hz})$ tone, respectively. The same maze was traced for twelve consecutive trials, leading to an effective overall training duration of $6 \mathrm{~min}$. In addition, the two square control conditions were presented in an interleaved fashion with respect to the two learning conditions (see Fig. 1a). Both control conditions consisted of six $30 \mathrm{~s}$ trials. In between the different tracing conditions, a $30 \mathrm{~s}$ 'switch' period was introduced in which the experimenter interchanged the mazes/ squares according to the experimental protocol. The condition order was counterbalanced across subjects.

On each following day, subjects repeatedly practiced one of the two mazes of the first scanning session more extensively during an additional set of twelve $30 \mathrm{~s}$ trials (Fig. 1b). These additional practice sessions were performed in a mock scanner, to ensure that the subjects would perform the required movements while lying in the same position as during the real scanning sessions. The specific maze which was extensively trained was varied across subjects, so that the sequence which was repeatedly practiced by six subjects functioned as the non-overlearned reference sequence for the other six subjects and vice versa. This approach ensured that any effects of extended practice cannot be attributed to a particular maze geometry per se, as not all subjects continued practicing the same sequence.

During the second scanning session (scheduled on Friday), there were three mazes which had to be traced following a similar scheme as in scanning session one (Fig. 1c). The mazes differed with respect to the amount of practice that had been invested in executing the corresponding movement sequence so far. With one maze, subjects were familiar because they had traced it in the first scanning session. However, no additional efforts were made to practice this particular sequence afterwards ('OLD'). Another maze was the one they had been practicing on a daily basis, in a total of 48 practice trials across 4 days, and which therefore was considered as overlearned ('OVER'). The final maze involved a trajectory which was completely new to the subjects ('NEW'). The six possible orders in which the three conditions could be presented were counterbalanced across subjects.

To exclude the possibility that subjects merely traced along the mazes' borders without actively learning the new movement patterns, they were asked to reproduce the learned movement 
a)

\section{Scanning Session 1 (Monday)}
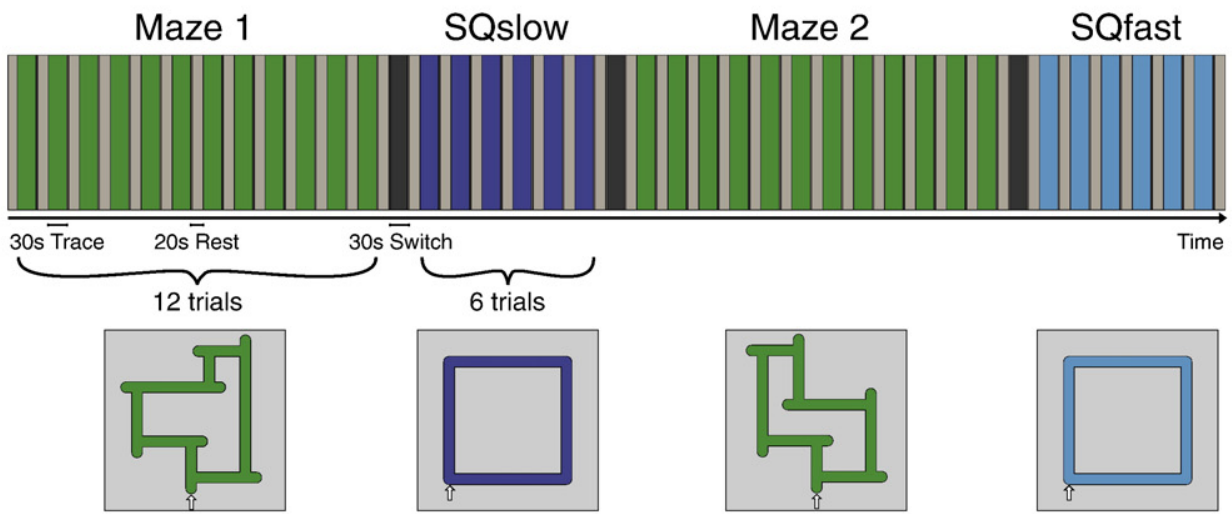

b)

\section{Training Sessions}
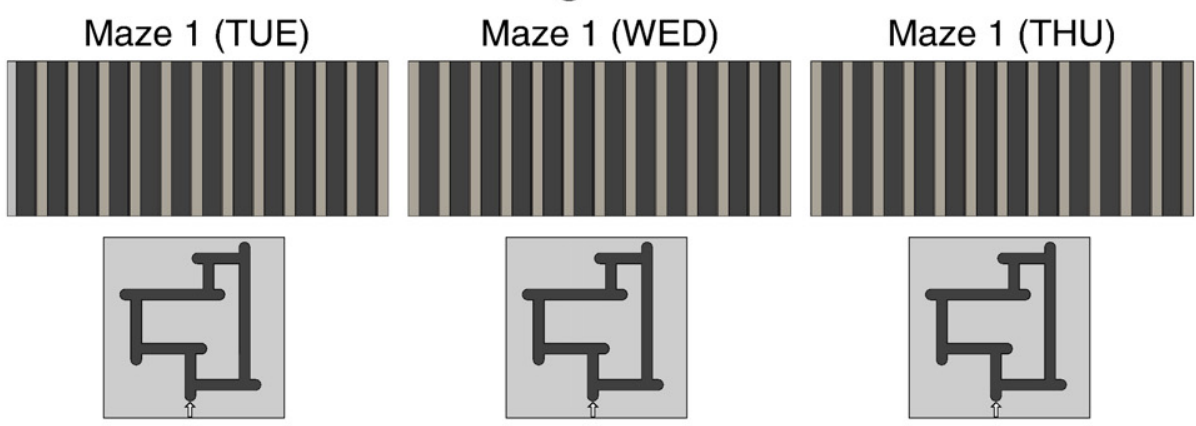

c)

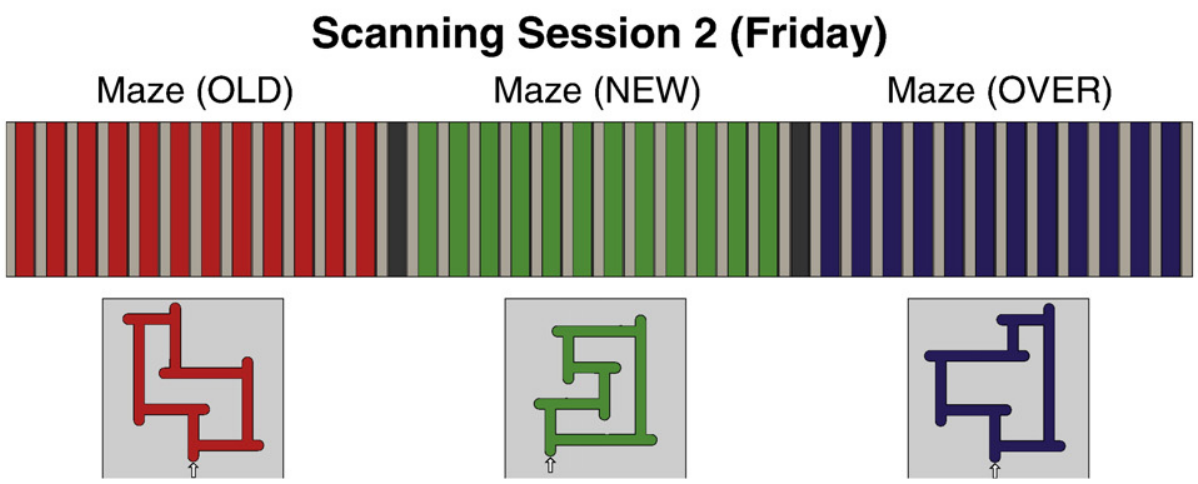

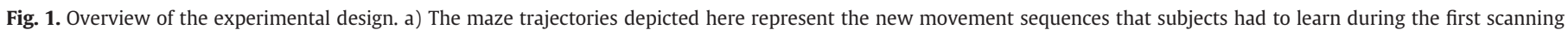

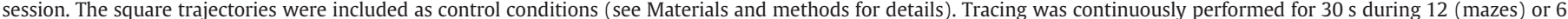

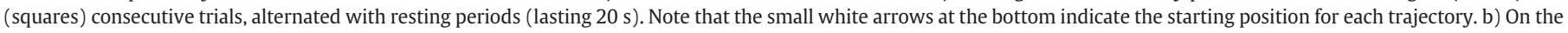

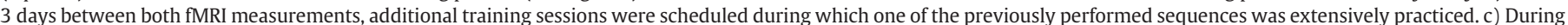

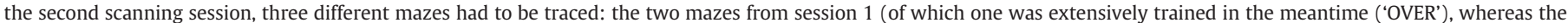

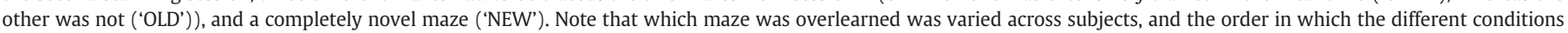

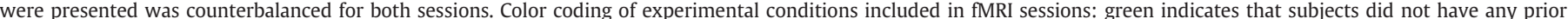

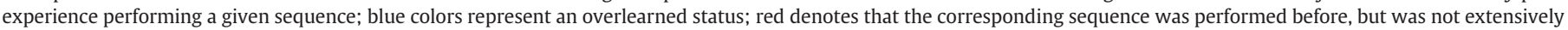
trained.

sequence by drawing the mazes by heart after each scanning- and practice-session (3 repetitions per maze). This 'free drawing' was performed using paper and pencil, while subjects still lay in the scanner and kept their eyes closed.

\section{Image acquisition}

Imaging data were collected on a 3 T Siemens Magnetom Allegra head-scanner (Siemens Medical Systems, Erlangen, Germany) via a regular volume coil. Both scanning sessions started with the acquisition of an anatomical 3D dataset consisting of 176 slices (MDEFT sequence (Deichmann et al., 2004); Repetition Time (TR) = $7.92 \mathrm{~ms}$; Echo Time $(\mathrm{TE})=2.4 \mathrm{~ms}$; Flip Angle $=15^{\circ}$, voxel dimensions $=1 \times 1 \times 1 \mathrm{~mm}^{3}$; Field of View $($ FoV $\left.)=256 \times 224 \mathrm{~mm}^{2}\right)$. Subsequently, 1576 functional volumes comprising 21 transversal slices were recorded using a gradient-echo echo-planar imaging sequence $\left(\mathrm{TR}=1250 \mathrm{~ms} ; \mathrm{TE}=28 \mathrm{~ms}\right.$; Flip Angle $=67^{\circ}$; voxel dimensions $=$ $3.5 \times 3.5 \times 5 \mathrm{~mm}^{3}$; gap $=1 \mathrm{~mm}$; FoV $=224 \times 224 \mathrm{~mm}^{2}$ ), resulting in 
complete coverage of the cerebrum while including the superior $2 / 3$ of the cerebellum. Functional data were collected in a single continuous run in order to minimize scanner-related changes in the overall signal level across conditions.

\section{Data analysis}

The acquired behavioral data were analyzed using in-house software written in MATLAB (v6.5 R13; The Mathworks, Natick, USA). Because of the high sampling rate at which the behavioral data were collected ( $\sim 666 \mathrm{~Hz}$; for details see Reithler et al., 2006), a TRbased binning could be used while extracting the most relevant performance measures: the mean velocity achieved, the percentage of samples being part of a stop, and finally the percentage of samples constituting a retrace. A stop was assigned whenever the tracing velocity was lower than $10 \mathrm{~mm} / \mathrm{s}$ during $100 \mathrm{~ms}$ or more. A retrace consisted of at least 150 consecutive samples which were traced in the wrong (i.e., counterclockwise) direction. Separate repeated measures Analyses of Variance (ANOVAs) were computed for all three performance measures to reveal how learning evolved within and across tracing conditions.

All imaging data were analyzed using BrainVoyager QX (v1.8; Brain Innovation, Maastricht, The Netherlands). The different analysis steps are described in detail below.

\section{Anatomical data}

The acquired anatomical datasets from both MR sessions were first corrected for spatial intensity inhomogeneities by estimating a bias field based on a preliminary white matter segmentation (Vaughan et al., 2001). For each subject, the dataset from the first scanning session was subsequently brought into ACPC space. Next, the datasets from both sessions were aligned using the ACPC version of the first dataset as the target volume and were separately transformed into standard Talairach space (Talairach and Tournoux, 1988). All performed transformations were then re-applied in a single step using sinc interpolation (Goebel et al., 2006) and both datasets were averaged. To optimize the 2D-3D alignment, the surrounding head tissue was removed using an automatic 'brain peeling' tool.

An additional processing step involved the semi-automatic segmentation of the grey and white matter boundary (Kriegeskorte and Goebel, 2001), followed by an inflation of the cortical surface. Finally, a cortex-based inter-subject alignment was separately performed for each hemisphere based on the individual brains' curvature information and using a moving target group averaging approach (Goebel et al., 2006). After the inter-subject alignment, a folded average cortex representation was constructed for both hemispheres, on which the statistical maps on the group level will be projected.

\section{Functional data}

Preprocessing of the individual datasets followed standard procedures optimized for the current application, and included the following steps: first, a slice scan time correction was performed using sinc interpolation to correct for the sequentially executed interleaved slice acquisition. Next, detection (trilinear interpolation) and correction (sinc interpolation) of 3D motion was performed to spatially align all functional volumes (of both sessions) to a single volume in the middle of the first scanning session using rigid-body transformations. Head motion of less than $3.5 \mathrm{~mm}$ (translation) or $3.5^{\circ}$ (rotation) relative to the target volume was deemed acceptable. Although the four initial volumes were excluded from further statistical analyses due to their stronger T1 saturation, the first volume was nevertheless coregistered to the middle volume in order to function as a reference with high anatomical detail during the intensity-driven fine tuning of the 2D-3D alignment later on. Following linear trend removal, highpass filtering was performed to remove low frequency drifts. Initially, a stringent cut-off of 12 cycles per time course $(0.0061 \mathrm{~Hz})$ was applied. Subsequently, the obtained results were confirmed using a more lenient high-pass filter setting (cut-off $=0,001 \mathrm{~Hz}$ ) to safeguard against false negatives. Except for the subcortical effects (for which stable baselines could only be obtained with more stringent filtering), all reported results are based on the $0.001 \mathrm{~Hz}$ high-pass filtered data. No spatial smoothing was applied.

The functional data were interpolated to a $3 \times 3 \times 3 \mathrm{~mm}^{3}$ voxel target resolution. In the context of the cortex-based inter-subject alignment procedure described in the previous section, sampling of the functional data was restricted to grey matter voxels based on the anatomical information from the individual cortex segmentations. The statistical analyses were carried out using a voxel-wise General Linear Model (GLM) at the single subject level, based on design matrices which included the estimated 3D motion parameters obtained during preprocessing as well as predictors for all relevant task conditions. An additional predictor was included to model the repositioning of the hand at the end of each tracing trial. For all trials within a condition, responses were separately modeled using a boxcar function which was convolved with a theoretical Two Gamma hemodynamic response function (Friston et al., 1998). These estimates of the trial responses relative to baseline were subsequently combined to provide an estimate of the condition effects, which could then be used to contrast the different experimental conditions. The reported group analyses were conducted following a random effects model. Unless stated otherwise, statistical group maps represent significant results at the $p<0.05$ level, corrected for multiple comparisons using cluster-size thresholding (based on an initial voxel level threshold set at $t \geq 3$ ). More detailed analyses were additionally performed for functionally defined Regions-of-Interest (ROIs) by running separate random effects ROI-GLMs. More specifically, the neural activation changes associated with learning were characterized in two ways. First, we divided the maze tracing conditions into an early and a late phase (similar to e.g. Floyer-Lea and Matthews, 2004). This categorization was based on the min-max normalized learning curve of the achieved mean velocity, extracted from the individual subject's behavioral data. Trials in which less than $25 \%$ of the maximum performance level was reached were classified as belonging to the early learning phase. The trials at the end of the maze tracing conditions in which a performance of $75-100 \%$ was achieved, were included in the late phase. Moreover, for each subject at least two trials were included in either phase to ensure a stable estimation of the individual activation levels. The second approach attempted to go beyond this early vs. late dichotomy by running analyses in which the individual subject's improvements in performance (as reflected by the increases in the z-transformed mean velocity achieved across trials) were included as separate predictors in the GLM (one for each maze tracing condition). By incorporating these behavioral performance predictors, the dynamic aspects of the ongoing learning process could be monitored more continuously, as they could reveal changes in neural activation levels on top of the involvement of a given area in the execution of the tracing movements per se (as captured by the more general binary on/off predictors for these conditions).

\section{Results}

\section{Scanning session 1 (day 1)}

\section{Behavioral data}

The registered pen tracing data were summarized and analyzed across subjects at the level of single trials. To identify potential effects of learning within a given condition, the first and last trial of that condition were contrasted as they constituted the two extremes with respect to the amount of preceding practice. 
First, a two-way repeated measures ANOVA with Maze (2 levels) and Trial (2 levels: 1 vs. 12 ) as within-subject factors was performed for all three performance measures. Significant 'Maze $\times$ Trial' interactions were found for velocity $\left(F_{(1,11)}=5.66 ; p=0.037\right)$ and stops $\left(F_{(1,11)}=9.56 ; p=0.010\right)$, whereas only significant main effects of Maze $\left(F_{(1,11)}=10.03 ; p=0.009\right)$ and Trial $\left(F_{(1,11)}=11.565 ; p=0.006\right)$ were observed for retraces. As can be seen in Fig. 2 (which shows the performance on the group level for all 3 behavioral measures), there was a significant increase in velocity accompanied by a decrease in the percentage of stops and retraces. For the first maze, the mean velocity increased from 17 to $45 \mathrm{~mm} / \mathrm{s}\left(F_{(1,11)}=34,16 ; p=0.000\right)$, and the stop and retrace percentages dropped from 53 to $26 \%$ and from 13 to $3 \%$, respectively (stops: $F_{(1,11)}=29.79 ; p=0.000$; retraces: $F_{(1,11)}=$ 7.38; $p=0.020$ ). A similar pattern of results was obtained for the second maze, although the level of the initial performance was higher compared to the first maze: the mean velocity increased from 30 to $51 \mathrm{~mm} / \mathrm{s}$ when comparing the first to the last trial $\left(F_{(1,11)}=22.73\right.$; $p=0.001$ ), while a decrease from 35 to $23 \%$ was found for the stop percentages $\left(F_{(1,11)}=8.58 ; p=0.014\right)$. There was only a trend with respect to a decrease in the retrace percentages (from 4 to $2 \% ; F_{(1,11)}=$ $4.74 ; p=0.052$ ). Finally, the mean velocity achieved during the square tracing was $28 \mathrm{~mm} / \mathrm{s}$ (standard error $(\mathrm{se})=1.5$ ) for the slow, and $68 \mathrm{~mm} / \mathrm{s} \quad(\mathrm{se}=2.4)$ for the fast tracing condition, indicating that subjects followed the instructions for these control conditions correctly.

\section{Imaging data}

In order to identify brain areas which were activated in all four tracing conditions of the first scanning session (i.e., irrespective of which movement sequence was performed), a contrast involving a conjunction across conditions versus baseline was calculated. As shown in Fig. 3 (indicated by white contours), the largest activation cluster was located within the left central sulcus, corresponding to the hand/wrist position within the somatotopic map of the primary motor (M1) and sensory (S1) cortices (Lotze et al., 2000; Alkadhi et al., 2002). The extent of this activation cluster further encompassed both the anterior bank of the precentral gyrus and part of the postcentral sulcus. Additionally, activations were observed in the left supplementary motor area (SMA) and the inferior postcentral sulcus. At the subcortical level, only unilateral activations emerged in the left putamen and thalamus, and the right cerebellum (not shown). Together these activations represent the basic network of areas associated with the execution of the required movements per se, irrespective of the specific trajectory or the level of proficiency. When performing the same contrast without including the square control conditions, the extent of the previously identified cortical network increased to encompass additional (bilaterally emerging) regions showing enhanced activation during the tracing of both mazes compared to baseline (see activation map in Fig. 3).

Because the movements in the current task were not externally paced, the possibility that learning-related changes in activity were confounded by corresponding changes in movement velocity needed to be ruled out. An additional contrast between the SQfast and SQslow conditions revealed that the previously mentioned left M1/S1 (see insert Fig. 3) and the ipsilateral right cerebellar foci were the only regions to show strict velocity-dependent responses as indicated by their significantly stronger response during the fast tracing condition. There were no regions which responded more strongly to the SQslow condition.

Based on the assumption that learning-related areas should be maximally engaged during the acquisition of the new movement sequences, a contrast between the two maze tracing and the two square conditions was computed (Fig. 4a). This contrast could be seen as an equivalent of a functional localizer, identifying possible candidate regions for further analyses, and resulted in the identification of a putative 'learning' network consisting of the following regions: the bilateral superior precentral sulcus at the level of the most caudal part of the superior frontal sulcus (dorsal premotor cortex, PMd), the bilateral anterior bank of the inferior precentral gyrus (ventral premotor cortex, PMv), the bilateral inferior postcentral sulcus (InfPCS), the bilateral anterior intraparietal sulcus (aIPS), the bilateral posterior superior parietal lobule (SPL), and a
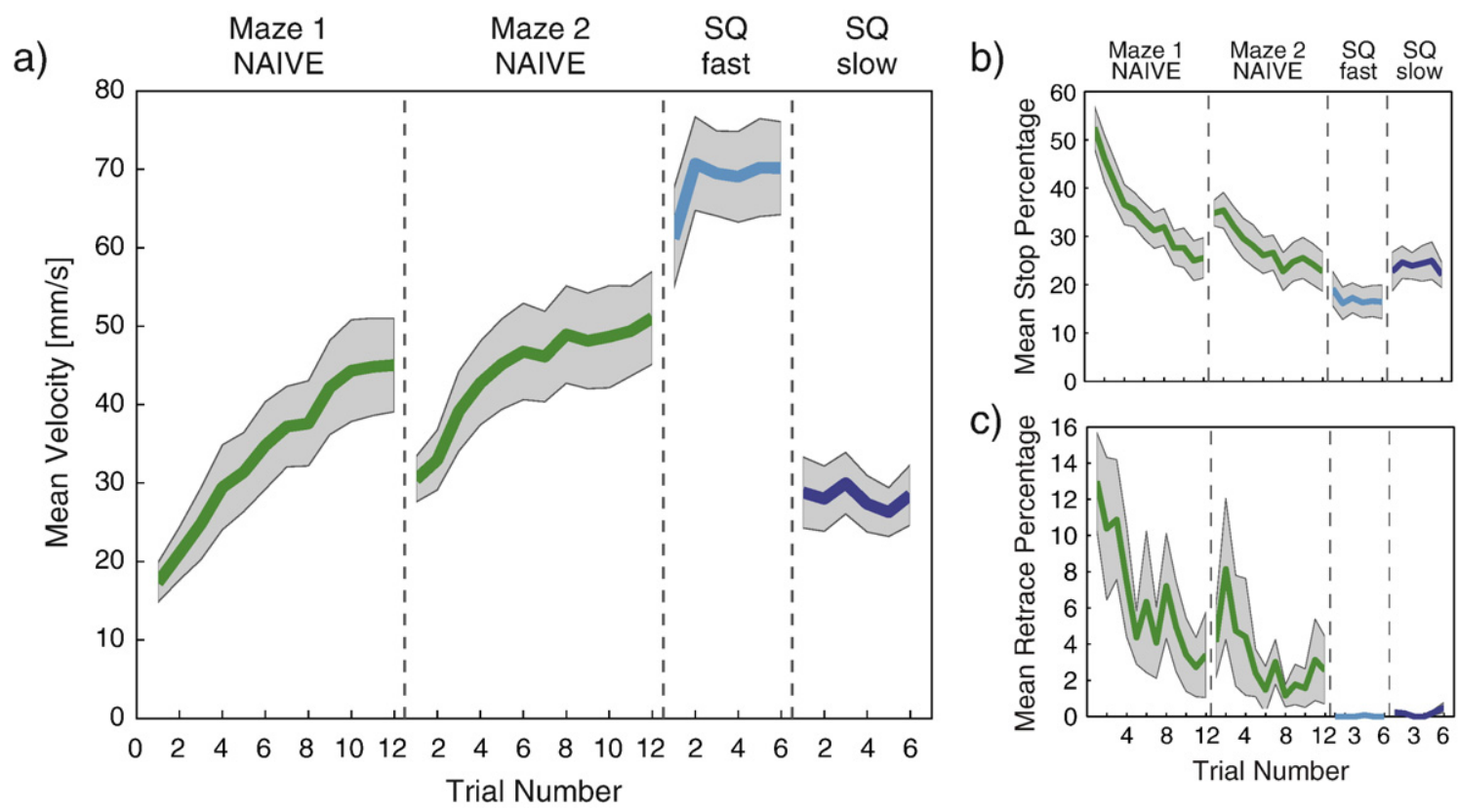

C)

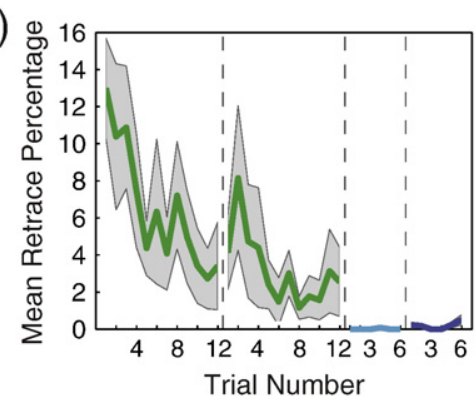

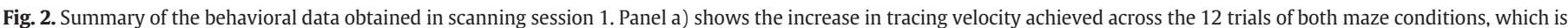

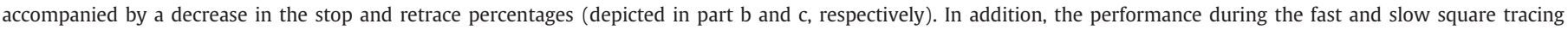

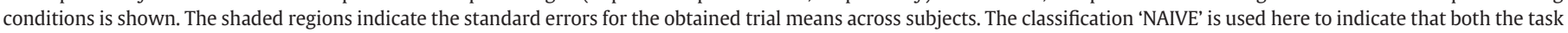

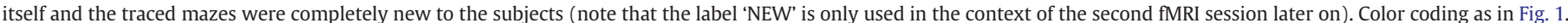




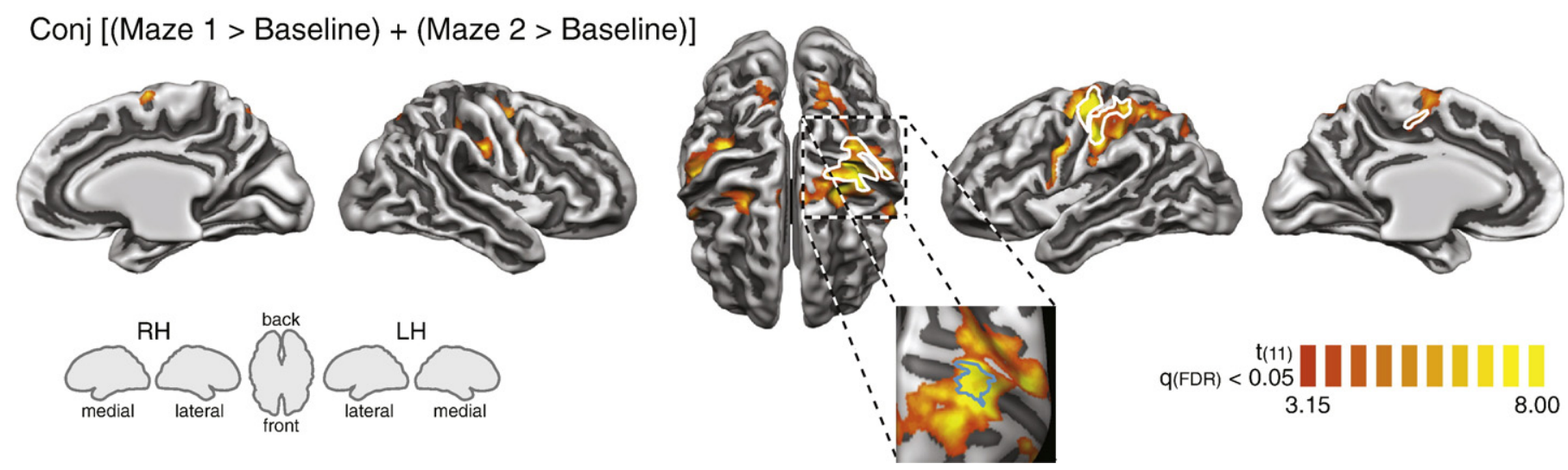

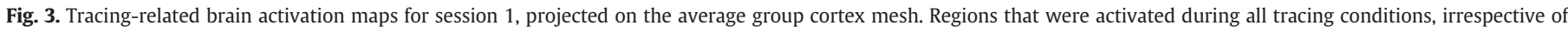

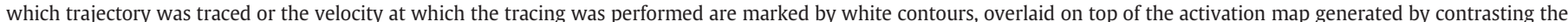

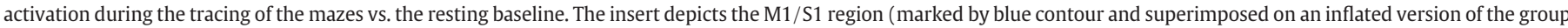

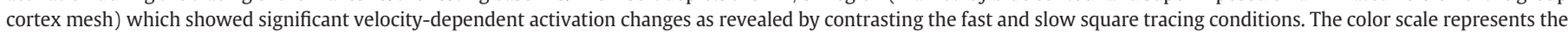

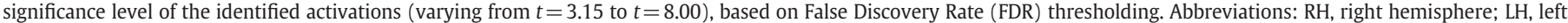
hemisphere.

region in the left medial IPS/posterior SPL (the corresponding Talairach coordinates are listed in Table 1). Besides showing markedly stronger responses in both learning conditions, most of these regions did not discriminate between the fast and the slow execution of the control sequences, suggesting their responses are not velocitydependent (Fig. 4b; for an overview of the responses in all identified ROIs see supplementary Fig. S1).

To further characterize the involvement of the aforementioned areas throughout the course of learning, both maze tracing conditions were divided into an early and a late phase as described in the Materials and methods section. Note that the numerals which are used to describe the mazes refer to the order of their presentation. The data from two subjects were excluded because their behavioral learning curves did not allow a clear distinction between learning phases. When using the previously designated 'learning-related' areas as ROIs, the following pattern of results was obtained when contrasting the learning phases for both mazes (see Table 1): while tracing maze 1 , moderate (i.e., only approaching corrected $p$-values) decreases in activation over time could be observed in the left PMd and bilateral aIPS, whereas more pronounced decreases were found for the right PMd, PMv, and the bilateral inferior postcentral sulcus. Clear activation decreases were present for all ROIs when comparing the two learning stages for the second maze. Furthermore, the learning-related decreases for maze 2 were confirmed by negative beta weights for the behavioral performance predictor, indicating decreases in activation with increases in performance over time (Table 1). As illustrated in Fig. 4b, similar responses for the two mazes were obtained when grouping the data according to their future classification instead of their current presentation order.

Finally, a contrast between the two control conditions was recomputed at the ROI-level (see last column Table 1), confirming that there was no significant difference between the fast and slow square tracing conditions in 6 out of 11 ROIs. The only ROI for which a corrected $p$-value was reached was the left InfPCS. However, the previously shown decreases in activation with increases in performance ensure that merely velocity-dependent activity modulations can be ruled out as a confounding factor.

To ensure that no interesting activation changes were missed by applying a ROI-based approach, the early and late phase of both maze tracing conditions were contrasted at the whole-brain level. The resulting maps supported the earlier observation that the decreases in activation in the identified ROIs were more pronounced for the second maze. Additionally, similar decreases in activation were observed in the right pre-SMA (Talairach coordinates $[\mathrm{x}, \mathrm{y}, \mathrm{z}$; in $\mathrm{mm}]: \mathrm{8}, 15,47$ ) and bilateral anterior insula (29,23,2 [right]; $-28,24,1$ [left]) for Maze 1 , and right (pre-)SMA $(6,-1,51)$, anterior insula $(29,20,3)$ and posterior IPS $(25,-67,37)$ for Maze 2.

\section{Training sessions (days 2-4)}

A two-way repeated measures ANOVA of the behavioral data gathered on the days in between the two scanning sessions with Session (Tuesday, Wednesday and Thursday) and Trial (trial numbers 1 and 12) as within-subject factors, revealed the following results: a significant interaction between Session and Trial emerged for the achieved velocity $\left(F_{(2,22)}=3.97 ; p=0.034\right)$, and significant main effects for both factors were found for the stop percentages (Session: $F_{(2,22)}=5.21 ; p=0.014 ;$ Trial: $\left.F_{(2,22)}=12.80 ; p=0.004\right)$. The retrace percentages did not show such effects. When comparing the first and last trial of each training session separately, a significant increase in velocity from 53 to $71 \mathrm{~mm} / \mathrm{s}\left(F_{(1,11)}=19.91 ; p=0.001\right)$ and a decrease in the stop percentage from 21 to $16 \%\left(F_{(1,11)}=5.20\right.$; $p=0.043$ ) were only found for the first training session (Tuesday). For the other two training sessions, no additional changes were detected for any of the behavioral measures, suggesting that a stable performance level was reached. After completing the three training sessions, the mean velocity achieved was $76 \mathrm{~mm} / \mathrm{s}(\mathrm{se}=7.4)$, while the stop and retrace percentages were $13 \%(\mathrm{se}=3.1)$ and $0.2 \%$ (se $=0.1$ ), respectively.

The free drawings that were produced after each training session furthermore suggested that all subjects could now reproduce the trained sequence correctly (when taking into account the number of drawn straight segments and their interrelated orientations).

\section{Scanning session 2 (day 5)}

\section{Behavioral data}

Three different maze tracing conditions were included in the second scanning session, allowing us to contrast the performance at different levels of proficiency. A two-way repeated measures ANOVA with Condition (overlearned, old and new) and Trial (1 vs. 12) as within-subjects factors revealed significant 'Condition by Trial' interactions for velocity $\left(F_{(2,22)}=6.55 ; p=0.006\right)$, as well as stops $\left(F_{(2,22)}=16.62 ; p=0.000\right)$, whereas for the retrace percentage, only a significant main effect for Trial was found $\left(F_{(1,11)}=7.244 ; p=0.021\right)$. Next, the first and last trials of the three tracing conditions were contrasted separately. Because performance on the overlearned sequence reached an asymptotic level during the previous training 


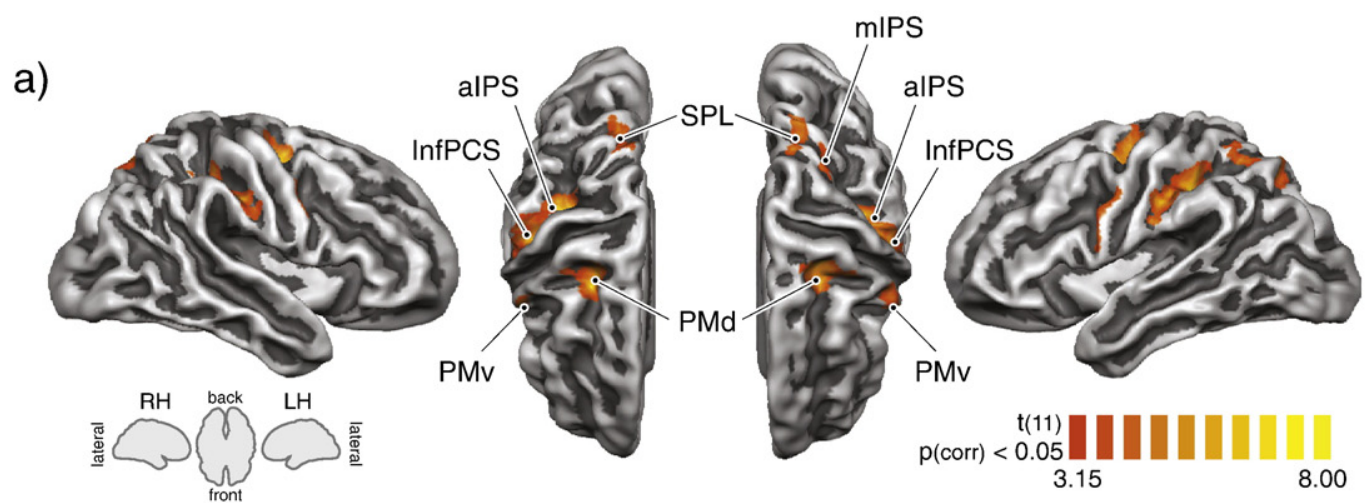

b)
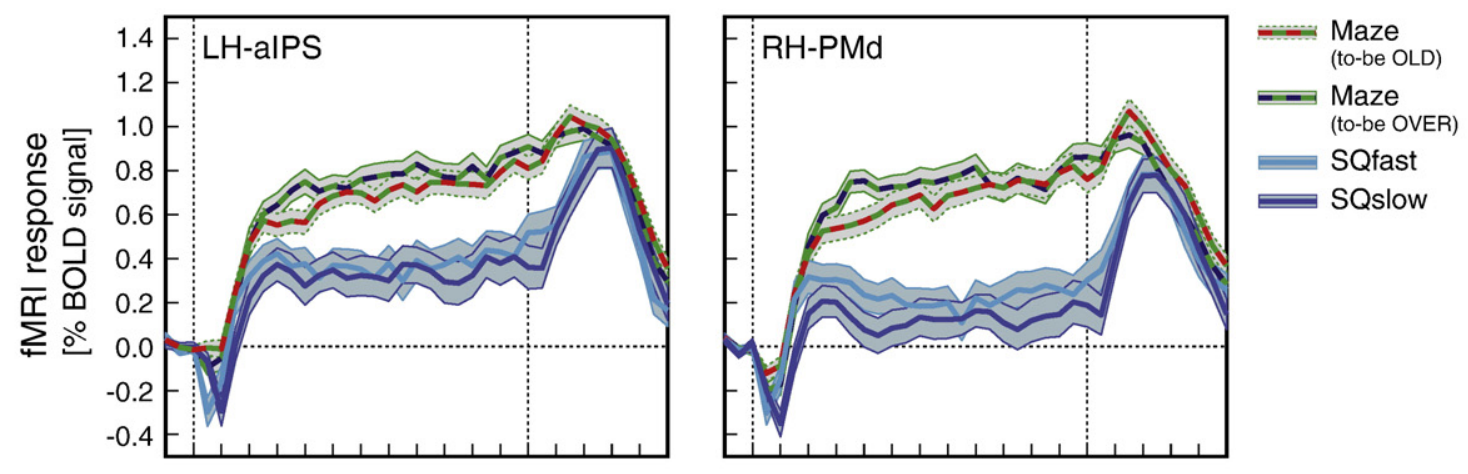

c)
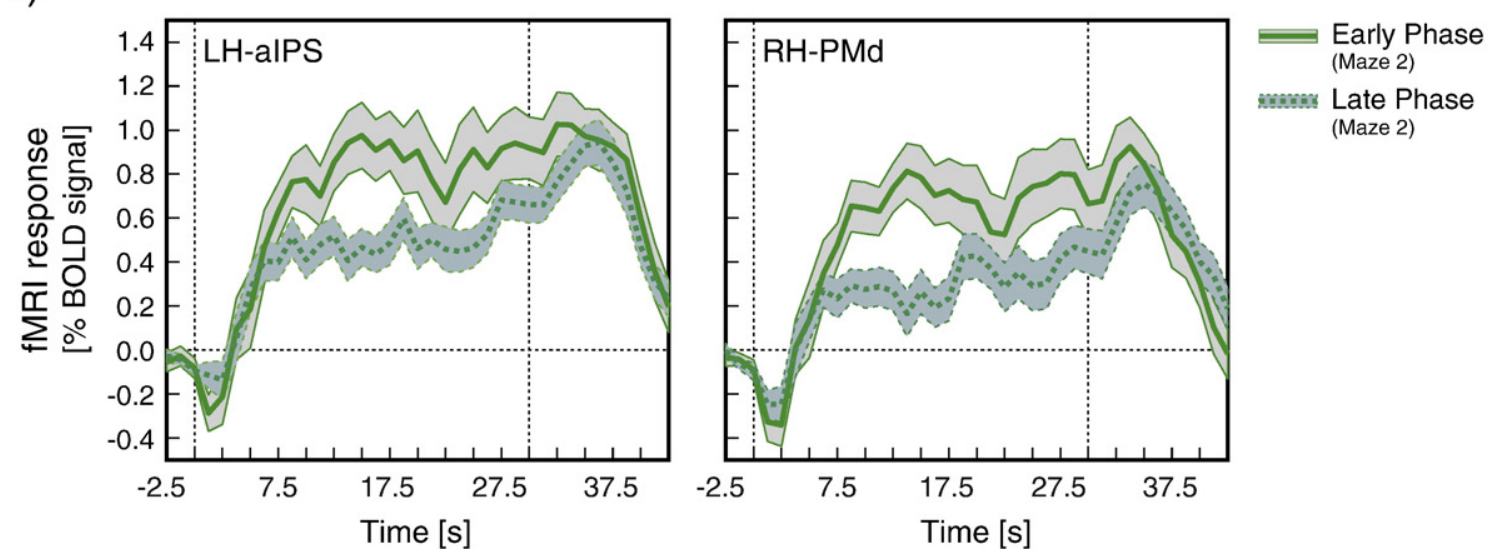

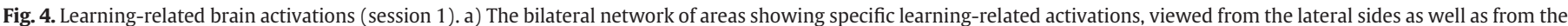

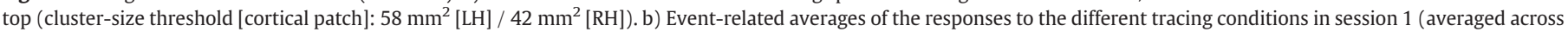

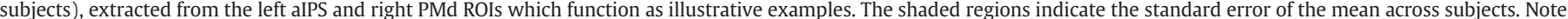

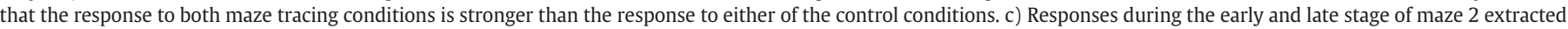

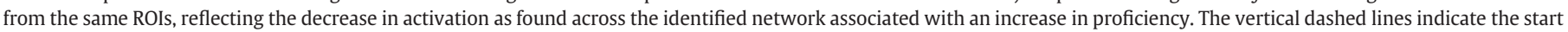

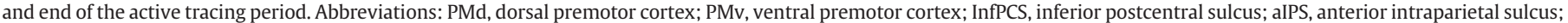
mIPS, medial intraparietal sulcus; SPL, superior parietal lobule; RH, right hemisphere; LH, left hemisphere.

sessions, no additional changes were expected to occur while subjects traced the extensively trained sequence again in the second scanning session ('OVER'). This was indeed the case for both the stop $\left(F_{(1,11)}=\right.$ $4.34 ; p=0.061)$ and retrace $\left(F_{(1,11)}=0.17 ; p=0.686\right)$ percentages. However, the velocity on the first trial did significantly differ from the twelfth trial $\left(F_{(1,11)}=6.72 ; p=0.025\right)$. As is visible in Fig. 5, this was due to a slower performance on the first trial (instead of a faster performance on the last trial) of the overlearned sequence compared to the previous sessions and therefore probably does not represent a genuine learning effect (see Discussion). In contrast, stronger changes in performance were expected for the sequence which was encoun- tered in the first scanning session, but was not trained extensively afterwards ('OLD'). This expectation was confirmed for both the achieved velocity (increasing from 51 to $65 \mathrm{~mm} / \mathrm{s} ; F_{(1,11)}=12.26$; $p=0.005$ ) and the percentage of stops (decreasing from 39 to $18 \%$; $F_{(1,11)}=40.89 ; p=0.000$ ). Finally, being confronted with a completely novel maze ('NEW') should also lead to changes in behavior across the presented repetitions. Such improvements in performance were indeed found for all behavioral measures: the velocity increased from 47 to $70 \mathrm{~mm} / \mathrm{s}\left(F_{(1,11)}=61.63 ; p=0.000\right)$, while the stop and retrace percentages decreased from 32 to $16 \%\left(F_{(1,11)}=34.91 ; p=0.000\right)$ and from 4 to $0 \%\left(F_{(1,11)}=5.34 ; p=0.041\right)$, respectively. 
Table 1

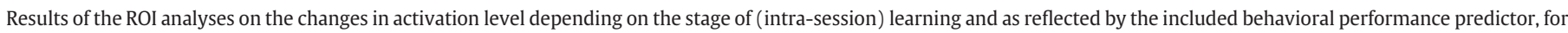

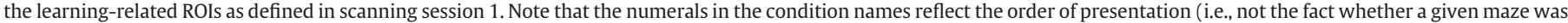
extensively trained afterwards or not).

\begin{tabular}{|c|c|c|c|c|c|c|c|c|c|c|c|c|}
\hline \multirow{3}{*}{$\begin{array}{l}\text { Region of } \\
\text { interest }\end{array}$} & \multirow[t]{3}{*}{ Hemisphere } & \multirow{2}{*}{\multicolumn{3}{|c|}{$\begin{array}{l}\text { Talairach coordinates } \\
\text { [mm] }\end{array}$}} & \multicolumn{8}{|c|}{ Significance of activation changes: $t$-values and probabilities for contrasts (RFX ROI-GLM; $n=10$ ) } \\
\hline & & & & & \multicolumn{2}{|c|}{$\begin{array}{l}\text { Maze } 1 \text { Early> } \\
\text { Maze } 1 \text { Late }\end{array}$} & \multicolumn{2}{|c|}{$\begin{array}{l}\text { Maze } 2 \text { Early> } \\
\text { Maze } 2 \text { Late }\end{array}$} & \multicolumn{2}{|c|}{$\begin{array}{l}\text { Maze } 2 \text { Behav } \\
\text { Perform Pred }\end{array}$} & \multicolumn{2}{|c|}{$\begin{array}{l}\text { Square Fast> } \\
\text { Square Slow }\end{array}$} \\
\hline & & $\mathrm{x}$ & $\mathrm{y}$ & $\mathrm{z}$ & $\mathrm{t}$ & $(p)$ & $\mathrm{t}$ & $(p)$ & $\mathrm{t}$ & $(p)$ & $\mathrm{t}$ & $(p)$ \\
\hline \multicolumn{13}{|l|}{ PMd } \\
\hline & $\mathrm{LH}$ & -24 & -10 & 53 & 3.10 & $(0.013)^{*}$ & 4.11 & $(0.003)^{* *}$ & -3.79 & $(0.004)^{* *}$ & 3.01 & $(0.015)^{*}$ \\
\hline & $\mathrm{RH}$ & 25 & -8 & 52 & 4.14 & $(0.003)^{* *}$ & 5.60 & $(0.000)^{* *}$ & -6.60 & $(0.000)^{* *}$ & 2.48 & $(0.035)^{*}$ \\
\hline \multicolumn{13}{|l|}{ PMv } \\
\hline & LH & -54 & 1 & 29 & 1.74 & $(0.115)$ & 8.74 & $(0.000)^{* *}$ & -9.29 & $(0.000)^{* *}$ & 0.79 & $(0.449)$ \\
\hline & $\mathrm{RH}$ & 52 & 3 & 33 & 4.30 & $(0.002)^{* *}$ & 6.72 & $(0.000)^{* *}$ & -8.98 & $(0.000)^{* *}$ & -0.10 & $(0.926)$ \\
\hline \multicolumn{13}{|l|}{ InfPCS } \\
\hline & $\mathrm{RH}$ & 50 & $\begin{array}{l}-23 \\
-24\end{array}$ & 37 & 4.99 & $(0.001)^{* *}$ & $\begin{array}{l}0.99 \\
5.21\end{array}$ & $(0.001)^{* *}$ & -5.06 & $(0.001)^{* *}$ & 2.21 & $(0.054)$ \\
\hline \multicolumn{13}{|l|}{ aIPS } \\
\hline & LH & -39 & -34 & 42 & 2.42 & $(0.039)^{*}$ & 8.15 & $(0.000)^{* *}$ & -6.37 & $(0.000)^{* *}$ & 2.42 & $(0.039)^{*}$ \\
\hline & $\mathrm{RH}$ & 36 & -35 & 42 & 3.38 & $(0.008)^{*}$ & 5.59 & $(0.000)^{* *}$ & -5.61 & $(0.000)^{* *}$ & 0.56 & $(0.588)$ \\
\hline MIPS & LH & -28 & -52 & 53 & 0.42 & $(0.684)$ & 4.22 & $(0.002)^{* *}$ & -5.18 & $(0.001)^{* *}$ & 0.90 & $(0.394)$ \\
\hline & $\mathrm{RH}$ & - & - & - & - & - & - & - & - & - & - & - \\
\hline \multicolumn{13}{|l|}{ SPL } \\
\hline & LH & -16 & -65 & 50 & -0.04 & $(0.967)$ & 3.69 & $(0.004)^{* *}$ & -4.01 & $(0.003)^{* *}$ & -2.15 & $(0.060)$ \\
\hline & $\mathrm{RH}$ & 14 & -63 & 54 & 0.85 & $(0.415)$ & 4.81 & $(0.001)^{* *}$ & -5.97 & $(0.000)^{* *}$ & -3.55 & $(0.006)^{*}$ \\
\hline
\end{tabular}

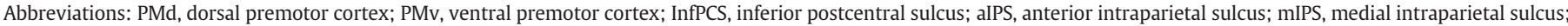
SPL, superior parietal lobule; LH, left hemisphere; $\mathrm{RH}$, right hemisphere.

* $p<0.05$ (uncorrected).

** $p<0.0045$ (Bonferroni-corrected for the number of included ROIs).

\section{Imaging data}

A first observation regarding the imaging data of the second fMRI session was that a highly similar network of areas was active across the different tracing conditions, i.e. irrespective of the amount of preceding practice. In close correspondence to the general maze tracing network as identified in the first scanning session (Fig. 3), separate contrasts for each condition against baseline resulted in remarkably overlapping activation patterns (Fig. 6). This implies that the amount of practice does not strongly affect the spatial layout of the engaged brain network: except for some right hemispheric nodes that seem to drop out, the same cortical areas stay involved throughout learning.

To assess the continuing involvement of areas that were previously designated to show learning-related activation changes, separate random effects contrasts were computed for the ROIs defined in the first session. However, due to the rapid changes in activation levels that can occur during learning (as was demonstrated above for scanning session 1), the effects of training were not examined by contrasting all trials of the different tracing conditions integrally. Instead, the behavioral data were again used to separate early from
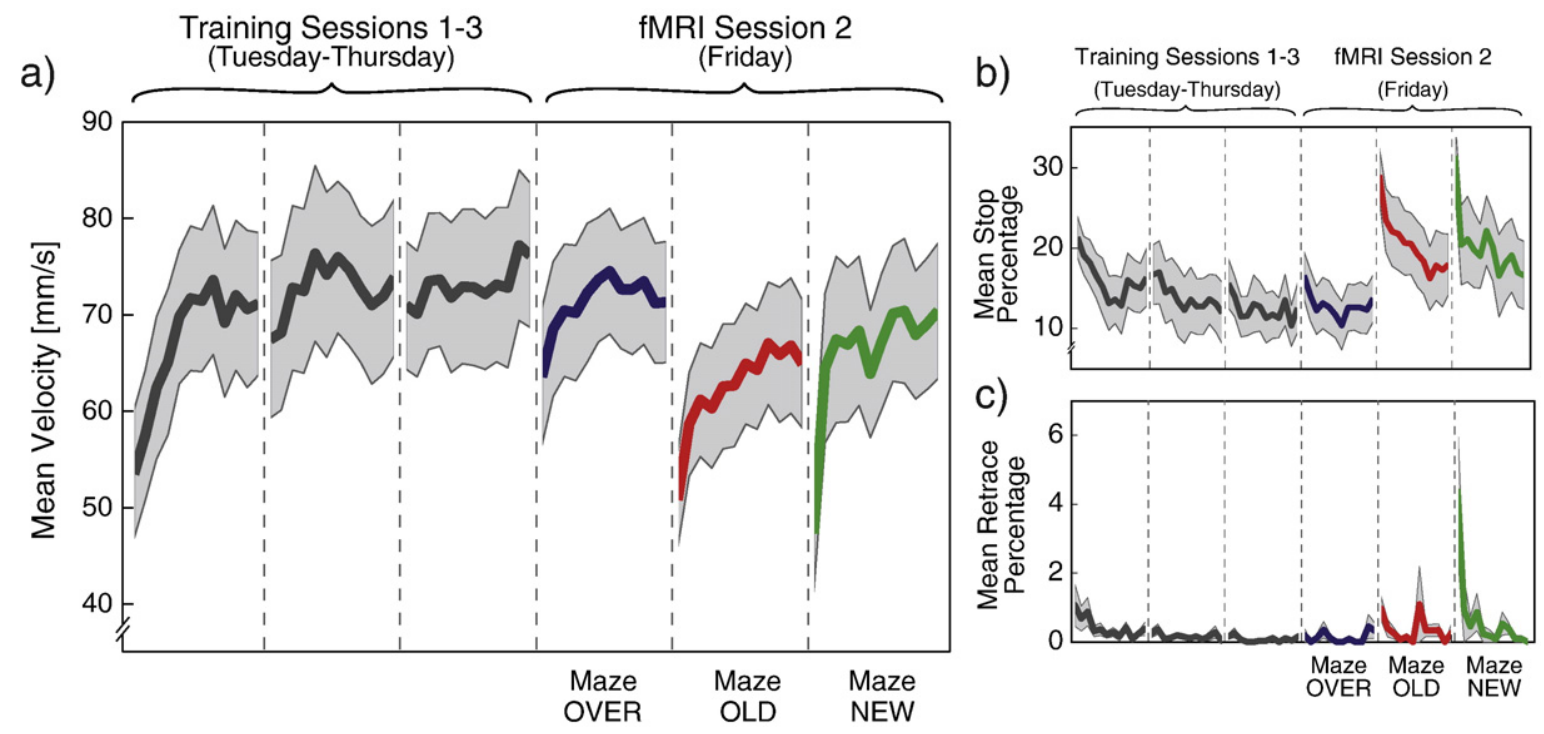

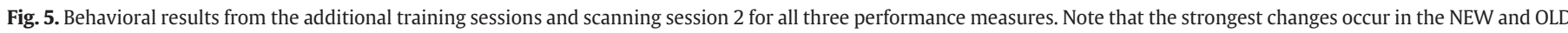
conditions. The shaded regions indicate the standard errors for the calculated trial means. Color coding as in Fig. 1. 
a) $\operatorname{Maze}(\mathrm{NEW})>$ Baseline
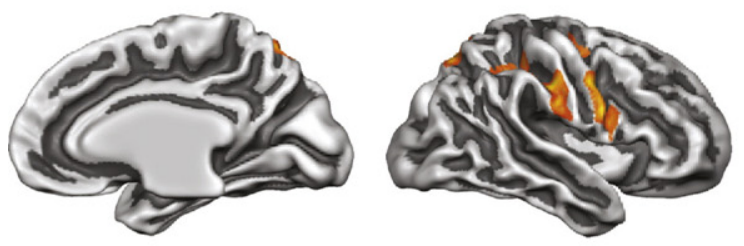

b) Maze(OLD) > Baseline
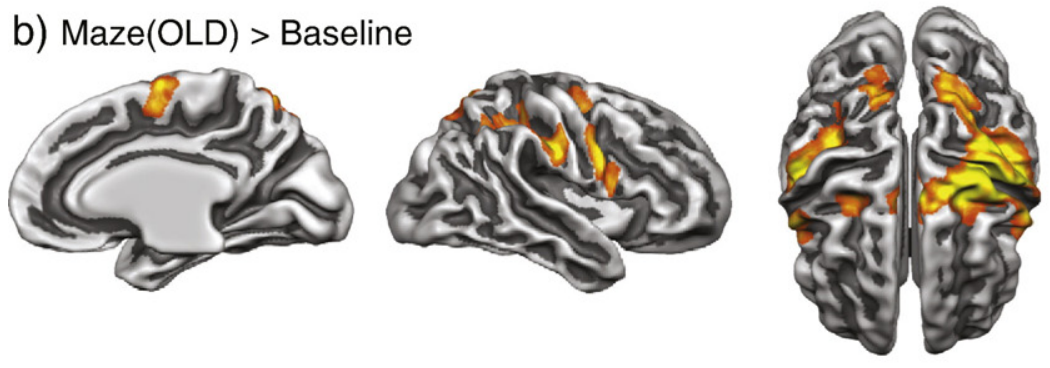

\section{c) Maze(OVER) > Baseline}
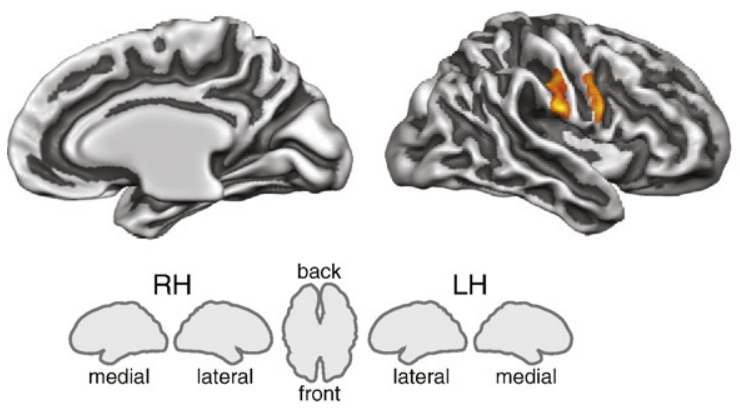
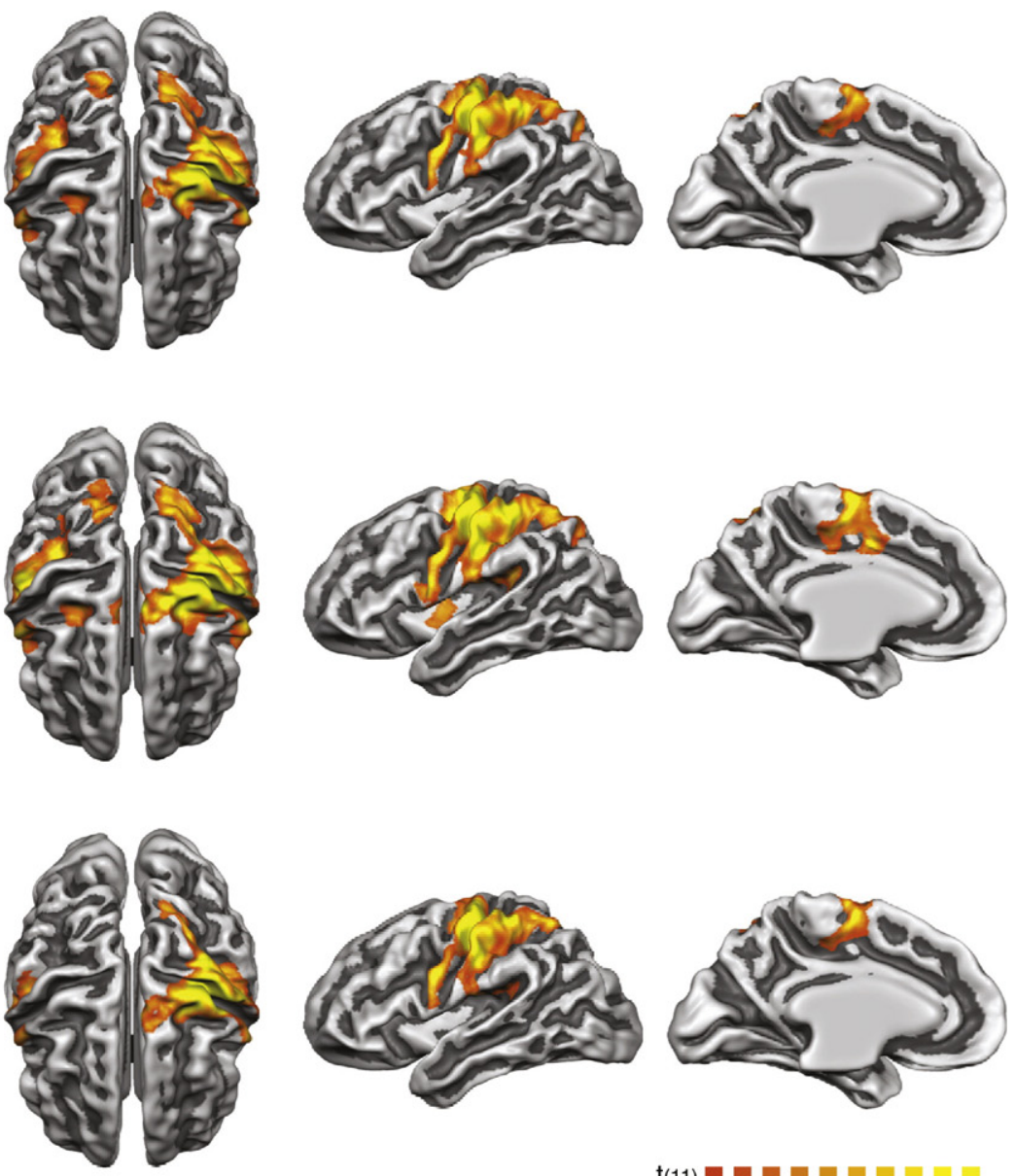

$\mathrm{p}(\mathrm{corr})<0.05$

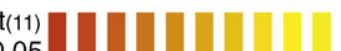

3.00

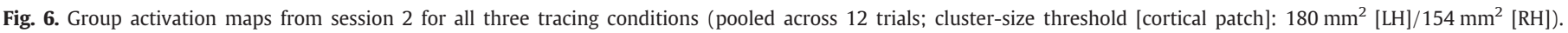

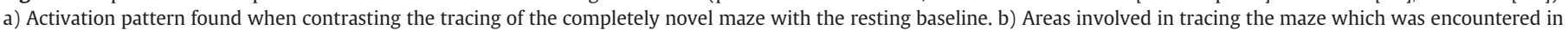

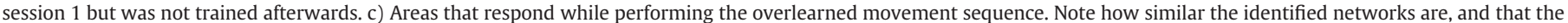

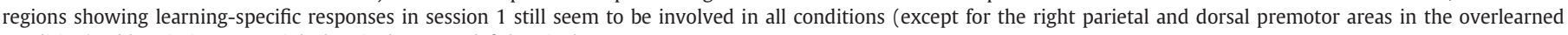
condition). Abbreviations: $\mathrm{RH}$, right hemisphere; $\mathrm{LH}$, left hemisphere.

late stages of (within-session) learning and to define the previously mentioned continuous performance predictors. One of the main findings was that all ROIs showed a significant decrease in activation during the tracing of the novel sequence as learning progressed. This effect was clearly present both when contrasting the early vs. late phase of the NEW condition (Table 2), as well as in the highly significant negative betas for the performance predictor indicating activation decreases with performance increases across all included ROIs ( $p \leq 0.0003$; see also Fig. 7).

Moreover, a similar learning-related decrease was observed throughout the entire network for the sequence which was previously encountered in session 1, but was not practiced any further afterwards (Table 2; Fig. 7). As expected if this previous experience would still have an effect, the overall difference between the early and late stage of learning was somewhat less pronounced compared to the completely novel case. Finally, the learning-related ROIs generally did not show a significant change in activation level for the overlearned sequence, presumably because no additional learning took place (Table 2; Fig. 7).

Because both the neural and behavioral probes of learning suggested that the novel sequence was learned relatively fast, the strongest divergence in activation levels between the novel and overlearned sequence would consequently be expected in the early stages of task execution. As shown in Table 2, the large majority of
ROIs ( $\geq 90 \%$ ) indeed responded more strongly during the initial stage of learning the new movement sequence than during the first trials of executing the overlearned sequence. Moreover, comparable results were obtained by directly contrasting the obtained beta weights for the NEW and OVER performance predictor (last column in Table 2). Stronger decreases over time were identified for the novel compared to the overlearned sequence as indicated by the (strong tendency [max. $p=0.006$ ] towards) more negative beta weights. Similar to what was found for the first scanning session, additional 'whole brain'-contrasts revealed that the amplitude of the right (pre-)SMA (Talairach coordinates: 6,9,46) and bilateral posterior IPS $(-26$, $-66,30$ [left]; 26,-66,36 [right]) response decreased when comparing early versus late performance on the 'NEW' sequence. Likewise, activation decreases with increases in performance were found for the 'OLD' sequence in bilateral (pre-)SMA ( $-8,9,47$ [left]; 6,9,46 [right]), posterior IPS ( $-24,-66,31$ [left]; 22,-69,38 [right]) and anterior insula ( $-30,16,2$ [left]; 30,19,5 [right]). No further decrease was observed for the overlearned movement pattern, consistent with the general response profile of the other areas as described above.

In contrast, the only region which did show an increased activation level during the early phase of executing the overlearned compared to the completely novel sequence was located in the left posterior putamen (Talairach coordinates: $-26,-11,13$ ). Only the performance predictor for the overlearned sequence reached significance in 
Table 2

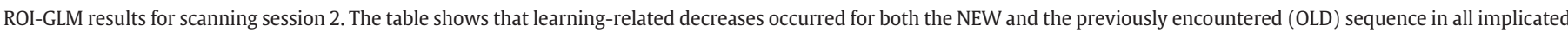

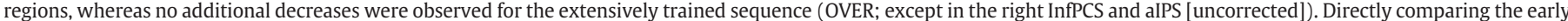

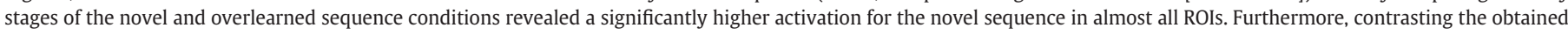

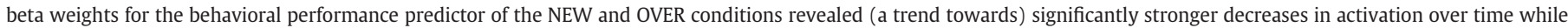
learning the novel sequence in all identified ROIs (see also Fig. 7).

\begin{tabular}{|c|c|c|c|c|c|c|c|c|c|c|c|}
\hline \multirow{3}{*}{$\begin{array}{l}\text { Region of } \\
\text { interest }\end{array}$} & \multirow[t]{3}{*}{ Hemisphere } & \multicolumn{10}{|c|}{ Significance of activation changes: $t$-values and probabilities for contrasts (RFX ROI-GLM; $n=12$ ) } \\
\hline & & \multicolumn{2}{|c|}{ NEW Early $>$ NEW Late } & \multicolumn{2}{|c|}{ OLD Early $>$ OLD Late } & \multicolumn{2}{|c|}{$\begin{array}{l}\text { OVER Early> } \\
\text { OVER Late }\end{array}$} & \multicolumn{2}{|c|}{$\begin{array}{l}\text { NEW Early> } \\
\text { OVER Early }\end{array}$} & \multicolumn{2}{|c|}{$\begin{array}{l}\text { NEW }>\text { OVER Behav } \\
\text { Perform Pred }\end{array}$} \\
\hline & & $t$ & $(p)$ & $t$ & $(p)$ & $t$ & $(p)$ & $t$ & $(p)$ & $t$ & $(p)$ \\
\hline \multicolumn{12}{|l|}{ PMd } \\
\hline & $\mathrm{LH}$ & 5.12 & $(0.000)^{* *}$ & 2.60 & $(0.025)^{*}$ & 0.13 & $(0.901)$ & 3.38 & $(0.006)^{*}$ & -4.08 & $(0.002)^{* *}$ \\
\hline & $\mathrm{RH}$ & 5.59 & $(0.000)^{* *}$ & 3.45 & $(0.005)^{*}$ & 0.37 & $(0.718)$ & 3.82 & $(0.003)^{* *}$ & -3.69 & $(0.004)^{* *}$ \\
\hline \multicolumn{12}{|l|}{ PMv } \\
\hline & LH & 5.39 & $(0.000)^{* *}$ & 7.81 & $(0.000)^{* *}$ & 0.40 & $(0.697)$ & 3.63 & $(0.004)^{* *}$ & -7.03 & $(0.000)^{* *}$ \\
\hline & $\mathrm{RH}$ & 13.36 & $(0.000)^{* *}$ & 6.18 & $(0.000)^{* *}$ & 1.32 & $(0.314)$ & 7.39 & $(0.000)^{* *}$ & -5.31 & $(0.000)^{* *}$ \\
\hline \multicolumn{12}{|l|}{ InfPCS } \\
\hline & $\mathrm{LH}$ & 5.98 & $(0.000)^{* *}$ & 3.87 & $(0.003)^{* *}$ & 1.94 & $(0.079)$ & 3.84 & $(0.003)^{* *}$ & -5.04 & $(0.000)^{* *}$ \\
\hline & $\mathrm{RH}$ & 9.66 & $(0.000)^{* *}$ & 4.36 & $(0.001)^{* *}$ & 2.30 & $(0.042)^{*}$ & 6.52 & $(0.000)^{* *}$ & -4.99 & $(0.000)^{* *}$ \\
\hline aIPS & LH & 6.52 & $(0.000)^{* *}$ & 3.11 & $(0.010)^{*}$ & 0.12 & $(0.906)$ & 5.94 & $(0.000)^{* *}$ & -4.33 & $(0.001)^{* *}$ \\
\hline & $\mathrm{RH}$ & 10.37 & $(0.000)^{* *}$ & 4.59 & $(0.001)^{* *}$ & 2.47 & $(0.031)^{*}$ & 3.88 & $(0.003)^{* *}$ & -3.47 & $(0.005)^{*}$ \\
\hline mIPS & LH & 4.79 & $(0.001)^{* *}$ & 5.61 & $(0.000)^{* *}$ & 0.62 & $(0.546)$ & 5.19 & $(0.000)^{* *}$ & -3.43 & $(0.006)^{*}$ \\
\hline & $\mathrm{RH}$ & - & - & - & - & - & - & - & - & - & - \\
\hline \multicolumn{12}{|l|}{ SPL } \\
\hline & $\mathrm{LH}$ & 4.70 & $(0.001)^{* *}$ & 3.96 & $(0.002)^{* *}$ & 0.61 & $(0.556)$ & 6.19 & $(0.000)^{* *}$ & -3.90 & $(0.002)^{* *}$ \\
\hline & $\mathrm{RH}$ & 5.18 & $(0.000)^{* *}$ & 5.44 & $(0.000)^{* *}$ & 0.67 & $(0.517)$ & 5.14 & $(0.000)^{* *}$ & -4.49 & $(0.001)^{* *}$ \\
\hline
\end{tabular}

Abbreviations as in Table 1

$* p<0.05$ (uncorrected).

** $p<0.0045$ (Bonferroni-corrected for the number of included ROIs).

this region $\left(t_{(11)}=-2.49 ; p<0.030\right)$ and differed significantly from the predictor for the new movement sequence $\left(t_{(11)}=-2.48 ; p<\right.$ 0.031). As depicted in Fig. 8, the observed dynamic changes in striatal involvement throughout learning reflected functional reorganizations linked to the subjects' proficiency level: during the initial scanning session, only the anterior portion if the left striatum (shown in green) was activated (without differentiating between the learning and control conditions). Later on, an intermediate zone (depicted in turquoise) was recruited which partially included the previously activated anterior portion during any of the phases for both the novel and overlearned maze in the second scanning session. And although the activation levels in this intermediate zone already tended towards stronger responses for the overlearned sequence, a truly significant preference for the extensively trained sequence was only found in the posterior putamen (shown in blue).

\section{Discussion}

The current study aimed to provide insights into the neural dynamics associated with the nonvisual motor learning of 2dimensional continuous movement sequences. Learning-related changes in brain activity were examined both within the time frame of a single scanning session and after several days of extended practice by including a second scanning session.

\section{Identified learning-related activations}

Executing the required pen tracing movements was accompanied by activations in a distributed network of regions, of which only the contralateral M1/S1 and ipsilateral cerebellar foci displayed clear velocity-dependent responses, in accordance with previous studies (e.g., Turner et al., 1998; Riecker et al., 2003). Several regions showed enhanced activation levels during the tracing of the mazes compared to either of the control conditions, and did not differentiate between the fast and slow square tracing conditions per se. This suggests that the observed responses were likely to reflect the ongoing learning process and were free from confounds related to concomitant increases in movement velocity. Even though the included control conditions did not explicitly control for changes in other movement parameters such as arm stiffness, they at least successfully controlled for the most influential of the three included behavioral measures, as the achieved velocity continued to show gradual increases over time when stops and retraces already reached asymptotic levels. The regions potentially involved in learning as identified by the 'mazes vs, squares' localizer were generally activated bilaterally, showing a high degree of symmetry across both hemispheres. Frontal differential activity was restricted to the dorsal and ventral premotor cortices, known to be involved in the preparation and execution of voluntary actions (Wise et al., 1997; Rizzolatti and Luppino, 2001), as well as the production and learning of specific movement sequences (e.g., Jueptner et al., 1997; Harrington et al., 2000). The remaining activations were all located in the parietal lobe, comprising areas which constitute the main sources of input to the premotor areas described above (Rizzolatti and Luppino, 2001). The most laterally located activation site was found in the bilateral inferior postcentral sulcus, which in humans has recently been classified as the most rostral part of the inferior parietal lobule based on cytoarchitectonic data (Caspers et al., 2006) and which is primarily connected to nearby somatosensory and parietal areas as shown in monkeys (Rozzi et al., 2006). Another lateral region was identified bilaterally in the anterior IPS, corresponding to the human homologue of the macaque AIP (anterior intraparietal) sulcus (Culham and Valyear, 2006), which is directly connected to the PMv (Rizzolatti et al., 1998) and is involved in visually-guided grasping (Castiello, 2005) and visuo-tactile integration (Grefkes et al., 2002). The more posterior activation in the left medial IPS/middle SPL constitutes another putative human homologue to a well-known area in the monkey, namely medial intraparietal area MIP (Grefkes and Fink, 2005). Medial IPS activity was previously reported in humans during goal-directed joystick movements towards visually presented targets, even in the absence of direct visual feedback (Grefkes et al., 2004) and mIPS has dense connections to the PMd in monkeys (Rizzolatti et al., 1998). The final 


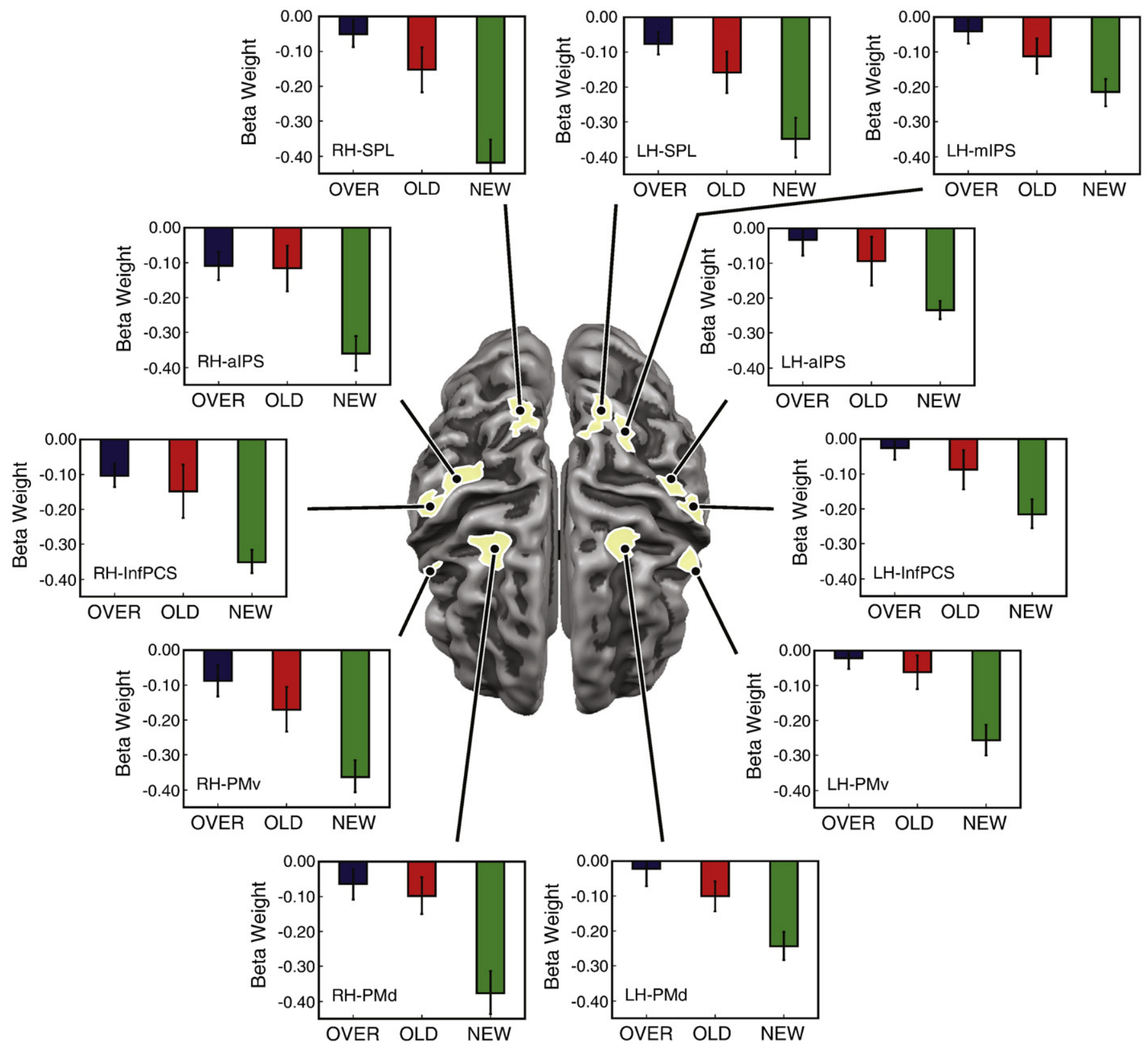

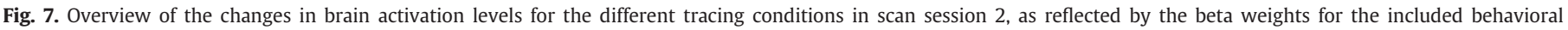

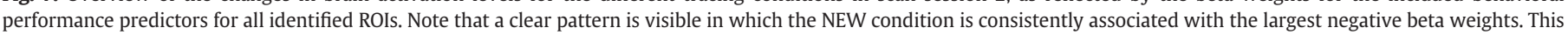

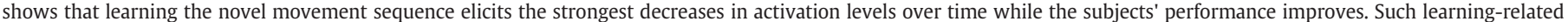

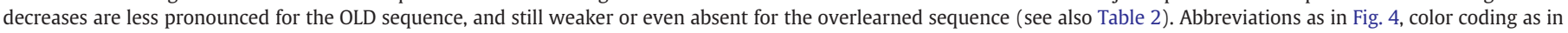
Fig. 1c.

activation site showing possible learning-related responses based on the functional localizer in the first scanning session was located in the posterior part of the SPL, adjacent to the medial IPS activity. Together these regions form the so-called parietal reach region (PRR) in the macaque, which has been associated with the control of reaching movements (e.g., Snyder et al., 1998) and the coding of so-called 'motor intentions', relatively abstract movement plans specifying both the goal of a movement and the type of movement required to achieve this goal (Andersen and Buneo, 2002; Quian Quiroga et al., 2006). However, similar posterior parietal activations have also been reported in the context of (both spatial and non-spatial) attention switches (Behrmann et al., 2004). In sum, a connected fronto-parietal network of regions predominantly implicated in the organization of sequential behavior and visuomotor transformations in the context of goal-directed movements, was shown here to also constitute a network of candidate regions involved in the learning of novel continuous movement sequences based on somatosensory and proprioceptive input alone. The involvement of the identified regions in learning was further substantiated based on the data from the second scanning session (see below).

Interestingly, no tracing- or learning-related activations were found in the dorso-lateral prefrontal cortex (DLPFC). Recruitment of the DLPFC might have been expected based on earlier SRT studies (Ashe et al., 2006) and reports on sequence-specific activation patterns identified using single-cell recordings (Averbeck et al., 2002, 2006). However, by varying the correspondence between behavioral goals and the movements required to achieve them, Mushiake et al. (2006) recently showed that the DLPFC does not 


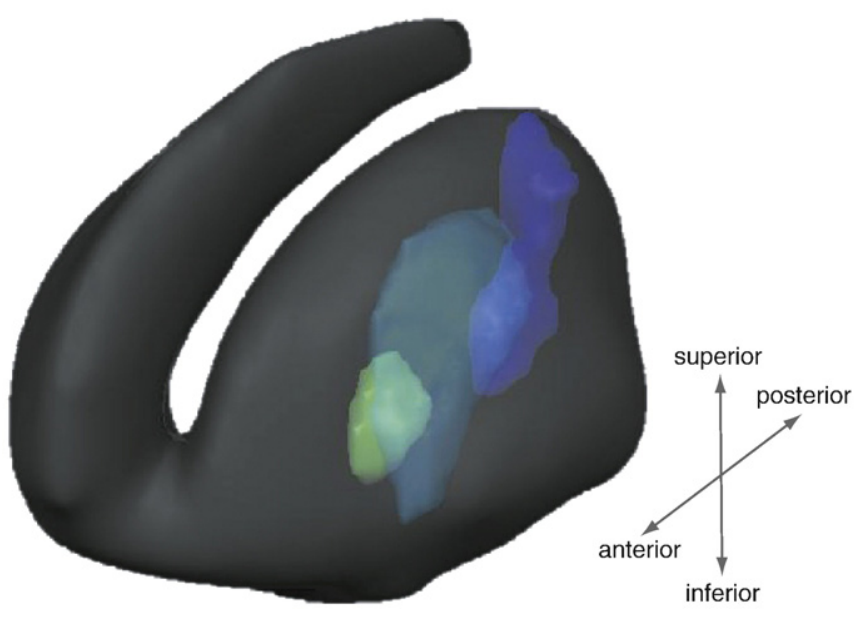

Fig. 8. Illustration of the involvement of the different portions of the left striatum throughout the course of learning. Whereas only the anterior striatum (in green) was indiscriminately activated initially, the second scanning session revealed an intermediate zone (in turquoise) that was active in all tracing conditions, yet showed a tendency towards stronger activations for the overlearned sequence. Finally, the posterior putamen (in blue) significantly showed a stronger response when directly comparing the early phase of the OVER and NEW condition.

necessarily code specific movement sequences, but rather their more abstract consequences in terms of behaviorally relevant subgoals (see also Saito et al., 2005). The lack of DLPFC involvement in the present experiment suggests that the task requirements were met at the motor system level, underlining the paradigm's focus on motor aspects of learning instead of its more cognitive and strategydependent characteristics. This is also in line with evidence provided by Robertson et al. (2001) suggesting that the DLPFC's role in SRT tasks is restricted to the processing of visuo-spatial cues, rather than the task's motor components.

\section{Brain activation changes over the course of learning}

Already within the first scanning session, the contributions of the areas listed above started to change while learning progressed. The more modest (or even absent) changes in activation level during the acquisition of the first sequence might be related to a familiarization process which masked the learning-related effects, as subjects still needed to become accustomed to the general task requirements and the experimental setting. This was also reflected by an apparent crossover effect in the behavioral data (better performance for maze 2 than maze 1 when comparing the first trials). However, one should keep in mind that such an order effect could not have negatively affected the present study's overall outcomes due to the counter balancing of conditions across subjects. This was also apparent from the similar responses that were obtained for both mazes when grouping the data according to their future classification ('to-be-OLD' and 'to-be-OVER') instead of their current presentation order.

Whereas the early practice-induced decreases in activation levels for the premotor and parietal areas are in accordance with earlier PET results based on the same paradigm, we found a similar decrease for the (pre-)SMA which was not reported previously (van Mier et al., 1998). Although the reason for this discrepancy is not entirely clear, it might be due to differences in design and general methodology (e.g., 10 to 20 min elapsed between the experimental and rest conditions in the PET experiment, instead of repeatedly being consecutively alternated). The finding that the (pre-)SMA is involved in all tracing conditions, but tends to become less active over time, points to a function in organizing multiple, separately performed movements in a correct temporal order (Tanji, 2001). With practice, these distinctly performed movements start to constitute a unified single movement pattern, thereby reducing the need to separately initiate and switch between its individual elements.

Interestingly, the experience-dependent decreases in brain activation observed in the first part of the current experiment were replicated 4 days later, in the second scanning session. Here, decreases were found both when a completely novel sequence was presented, and when learning continued on the maze which was traced previously in session 1 but was not extensively trained afterwards. Conversely, no such additional intra-session learning was found for the overlearned sequence. The slight dip (compared to the previous training sessions) which was present in the performance data for the overlearned condition in the second scanning session was probably related to the fact that subjects did not know in which order the conditions would be presented, and the possibility that subjects were initially more cautious compared to the situation in the dummy scanner (e.g., trying harder to prevent excessive head motion). As each subject had practiced this particular movement sequence several hundred times across 4 days (leaving ample time for offline skill consolidation) and performance reached (yet did not surpass) the previously achieved asymptotic level, the extensively trained sequence could safely be labeled as overlearned (at the very least in comparison to the other encountered sequences). Note that these results further substantiate the role of the identified cortical network in continuous sequence learning, as more general effects of task familiarity or differences in low-level features of the traced trajectories across conditions (which could still have played a role in session 1) cannot account for the obtained practice-dependent responses in session 2. In addition, contributions by other non-specific factors such as fatigue, overall motivation or the mere passage of time can be ruled out due to the counterbalancing of the tracing conditions. Similarly, the observed effects are not restrictively attributable to the specific features of any one particular trajectory, as the sequence which was overlearned differed across subjects. Finally, the changes in neural activation levels parametrically varied across three different levels of behavioral proficiency, thereby extending earlier work in which only two levels of expertise were probed by introducing a new control sequence at each scanning session (e.g., Lehericy et al., 2005). These findings stress the specificity of the observed learning-related activations, and provide a clear illustration of practice-induced changes in neural processing. It should be noted though that these observations pertain to the chosen time window. More prolonged training over periods of weeks or even months might reveal increases in the extent of activation or specific fine-grained changes in response patterns in particular circumscribed brain areas (such as M1, as suggested by the work of e.g., Karni et al. (1995) or Matsuzaka et al. (2007), respectively) that could not be captured here. Additionally, in future studies it might be interesting to focus more on potential changes in resting baseline activity and/or task-related deactivations over time that might be linked to the ongoing learning process (Kincses et al., 2008; Albert et al., 2009; Xiong et al., 2009).

Another aspect of the obtained results was that even though the activation levels of the identified regions markedly decreased with practice, there was a substantial overlap in the spatial layout of activation patterns across sessions and levels of proficiency. This consistency indicates that a similar network of regions is engaged throughout the course of skill acquisition, although the required processing is performed more efficiently as learning evolves. Increases in neural efficiency refer to optimizations (in computation or representation) leading to stable or improved processing while minimizing concomitant costs in terms of attentional or metabolic resources. Both within the skill acquisition literature (e.g., Aizawa et al., 1991) and other domains (e.g., Mukai et al., 2007), learningrelated decreases in activation are commonly thought to indicate increases in neural efficiency (even though it is not evident whether 
reduced BOLD signals represent changes in the number or the gain of recruited neurons within a given region; Poldrack, 2000). Such an interpretation is in line with recent results from studies investigating extended motor learning across multiple scanning sessions (de Weerd et al., 2003; Wu et al., 2004; Poldrack et al., 2005), as well as studies contrasting the neural correlates of learning in novices versus experts (Haslinger et al., 2004; Meister et al., 2005).

On the other hand, models on motor sequence learning have proposed dynamic shifts in activation patterns, leading to increased or more focused involvement of subcortical structures in later learning stages (Doyon and Benali, 2005; Ashe et al., 2006; Doyon et al., 2009). Although the subcortical activations identified in the first session of the current study were neither specifically involved in learning nor restricted to a particular time window, differential responses were found for the posterior putamen in the second scanning session. This structure was more strongly engaged during the early phase of tracing the overlearned compared to the novel maze, pointing to a function in the re-instatement of a previously learned movement set (Miyachi et al., 1997, 2002; Lehericy et al., 2005; and in partial agreement with Jankowski et al., 2009). Such a shift is in line with the framework presented by Doyon and Benali (2005), in which they revise their previous notion of the cortico-striatal system believed to be specifically involved in sequence learning (as opposed to the cortico-cerebellar system mainly involved in adaptation learning), by allowing activation shifts within each of these specialized systems. In addition, by showing that the posterior putamen is mainly engaged in later stages of skill acquisition in the current task, the presented data corroborate the work by Lehericy et al. (2005), on which the revision of the framework by Doyon and Benali (2005) was partially based, in two ways. First, our results indicate that a similar shift also occurs when continuous (instead of discrete) movement sequences are learned. Second, we show that the observed shift within the cortico-striatal network is also apparent in conditions were the task execution is self-paced (instead of externally paced). This distinction is important because employing external pacing necessarily implies restricting the subjects' motor output to a level which lies below their potential maximum (an effect which becomes more pronounced in later learning stages). Observing a similar shift in the absence of such a refrainment imposed by external pacing indicates that the activation pattern of the posterior putamen is not related to more prominently emerging inhibition processes.

In sum, the current results suggest that continuous motor sequence learning is characterized by practice-induced activation decreases throughout a cortical network of learning-related regions consistently engaged at different levels of proficiency. Concomitantly, a specific and circumscribed spatiotemporal activation gradient (along an anterior-to-posterior axis as learning progressed) was identified in the left putamen, in line with recent models on skill acquisition.

\section{Acknowledgments}

We thank Bettina Sorger for providing helpful suggestions and Judith Peters for her invaluable contributions during several stages of this project.

\section{Appendix A. Supplementary data}

Supplementary data associated with this article can be found, in the online version, at doi:10.1016/j.neuroimage.2010.03.073.

\section{References}

Aizawa, H., Inase, M., Mushiake, H., Shima, K., Tanji, J., 1991. Reorganization of activity in the supplementary motor area associated with motor learning and functional recovery. Exp. Brain Res. 84, 668-671.
Albert, N.B., Robertson, E.M., Miall, R.C., 2009. The resting human brain and motor learning. Curr. Biol. 19, 1023-1027.

Alkadhi, H., Crelier, G.R., Boendermaker, S.H., Golay, X., Hepp-Reymond, M.-C., Kollias, S.S., 2002. Reproducibility of primary motor cortex somatotopy under controlled conditions. Am. J. Neuroradiol. 23, 1524-1532.

Andersen, R.A., Buneo, C.A., 2002. Intentional maps in posterior parietal cortex. Annu. Rev. Neurosci. 25, 189-220.

Ashe, J., Lungu, O.V., Basford, A.T., Lu, X., 2006. Cortical control of motor sequences. Curr. Opin. Neurobiol. 16, 213-221.

Averbeck, B.B., Chafee, M.V., Crowe, D.A., Georgopoulos, A.P., 2002. Parallel processing of serial movements in prefrontal cortex. Proc. Natl Acad. Sci. USA 99, 13172-13177.

Averbeck, B.B., Sohn, J.W., Lee, D., 2006. Activity in prefrontal cortex during dynamic selection of action sequences. Nat. Neurosci. 9, 276-282.

Behrmann, M., Geng, J.J., Shomstein, S., 2004. Parietal cortex and attention. Curr. Opin. Neurobiol. 14, 212-217.

Bischoff-Grethe, A., Goedert, K.M., Willingham, D.T., Grafton, S.T., 2004. Neural substrates of response-based sequence learning using fMRI. J. Cogn. Neurosci. 16, 127-138.

Caspers, S., Geyer, S., Schleicher, A., Mohlberg, H., Amunts, K., Zilles, K., 2006. The human inferior parietal cortex: cytoarchitectonic parcellation and interindividual variability. Neuroimage 33, 430-448.

Castiello, U., 2005. The neuroscience of grasping. Nat. Rev. Neurosci. 6, 726-736.

Clegg, B.A., DiGirolamo, G.J., Keele, S.W., 1998. Sequence learning. Trends Cogn. Sci. 2, 275-281.

Culham, J.C., Valyear, K.F., 2006. Human parietal cortex in action. Curr. Opin. Neurobiol. $16,205-212$.

Culham, J.C., Cavina-Pratesi, C., Singhal, A., 2006. The role of parietal cortex in visuomotor control: what have we learned from neuroimaging? Neuropsychologia 44, 2668-2684.

de Weerd, P., Reinke, K., Ryan, L., Mclsaac, T., Perschler, P., Schnyer, D., Trouard, T., Gmitro, A., 2003. Cortical mechanisms for acquisition and performance of bimanual motor sequences. Neuroimage 19, 1405-1416.

Deichmann, R., Schwarzbauer, C., Turner, R., 2004. Optimisation of the 3D MDEFT sequence for anatomical brain imaging: technical implications at 1.5 and $3 \mathrm{~T}$. Neuroimage 21, 757-767.

Doyon, J., Benali, H., 2005. Reorganization and plasticity in the adult brain during learning of motor skills. Curr. Opin. Neurobiol. 15, 161-167.

Doyon, J., Ungerleider, L.G., 2002. Functional anatomy of motor skill learning. In: Squire, L.R., Schacter, D.L. (Eds.), Neuropsychology of Memory. Guilford Press, New York (NY), pp. 225-238.

Doyon, J., Penhune, V., Ungerleider, L.G., 2003. Distinct contribution of the corticostriatal and the cortico-cerebellar systems to motor skill learning. Neuropsychologia 41, 252-262.

Doyon, J., Bellec, P., Amsel, R., Penhune, V., Monchi, O., Carrier, J., Lehericy, S., Benali, H., 2009. Contributions of the basal ganglia and functionally related brain structures to motor learning. Behav. Brain Res. 199, 61-75.

Floyer-Lea, A., Matthews, P.M., 2004. Changing brain networks for visuomotor control with increased movement automaticity. J. Neurophysiol. 92, 2405-2412.

Friston, K.J., Fletcher, P., Josephs, O., Homes, A., Rugg, M.D., Turner, R., 1998. Eventrelated fMRI: characterizing differential responses. Neuroimage 7, 30-40.

Goebel, R., Esposito, F., Formisano, E., 2006. Analysis of functional image analysis contest (FIAC) data with BrainVoyager QX: from single-subject to cortically aligned group General Linear Model Analysis and self-organizing group Independent Component Analysis. Hum. Brain Mapp. 27, 392-401.

Grefkes, C., Fink, G.R., 2005. The functional organization of the intraparietal sulcus in humans and monkeys. J. Anat. 207, 3-17.

Grefkes, C., Weiss, P.H., Zilles, K., Fink, G.R., 2002. Crossmodal processing of object features in human anterior intraparietal cortex: an fMRI study implies equivalencies between humans and monkeys. Neuron 35, 173-184

Grefkes, C., Ritzl, A., Zilles, K., Fink, G.R., 2004. Human medial intraparietal cortex subserves visuomotor coordinate transformation. Neuroimage 23, 1494-1506.

Harrington, D.L., Rao, S.M., Haaland, K.Y., Bobholz, J.A., Mayer, A.R., Binder, J.R., Cox, R.W., 2000. Specialized neural systems underlying representations of sequential movements. J. Cogn. Neurosci. 12, 56-77.

Haslinger, B., Erhard, P., Altenmueller, E., Hennenlotter, A., Schwaiger, M., Graefin von Einsiedel, H., Rummeny, E., Conrad, B., Ceballos-Baumann, A., 2004. Reduced recruitment of motor association areas during bimanual coordination in concert pianists. Hum. Brain Mapp. 22, 206-215.

Jankowski, J., Scheef, L., Huppe, C., Boecker, H., 2009. Distinct striatal regions for planning and executing novel and automated movement sequences. Neuroimage 44, 1369-1379.

Jueptner, M., Stephan, K.M., Frith, C.D., Brooks, D.J., Frackowiak, R.S.J., Passingham, R.E., 1997. Anatomy of motor learning. I. Frontal cortex and attention to action. J. Neurophysiol. 77, 1313-1324.

Karni, A., Meyer, G., Jezzard, P., Adams, M.M., Turner, R., Ungerleider, L.G., 1995. Functional MRI evidence for adult motor cortex plasticity during motor skill learning. Nature 377, 155-158.

Keele, S.W., Ivry, R., Mayr, U., Hazeltine, E., Heuer, H., 2003. The cognitive and neural architecture of sequence representation. Psychol. Rev. 110, 316-339.

Kelly, A.M.C., Garavan, H., 2005. Human functional neuroimaging of brain changes associated with practice. Cereb. Cortex 15, 1089-1102.

Kincses, Z.T., Johansen-Berg, H., Tomassini, V., Bosnell, R., Matthews, P.M., Beckmann, C.F., 2008. Model-free characterization of brain functional networks for motor sequence learning using fMRI. Neuroimage 39, 1950-1958.

Kriegeskorte, N., Goebel, R., 2001. An efficient algorithm for topologically correct segmentation of the cortical sheet in anatomical MR volumes. Neuroimage 14, 329-346. 
Lehericy, S., Benali, H., van de Moortele, P.-F., Pelegrini-Issac, M., Waechter, T., Ugurbil, K., Doyon, J., 2005. Distinct basal ganglia territories are engaged in early and advanced motor sequence learning. Proc. Natl Acad. Sci. USA 102, 12566-12571.

Lotze, M., Erb, M., Flor, H., Huelsmann, E., Godde, B., Grodd, W., 2000. fMRI evaluation of somatotopic representation in human primary cortex. Neuroimage 11, 473-481.

Matsuzaka, Y., Picard, N., Strick, P.L., 2007. Skill representation in the primary motor cortex after long-term practice. J. Neurophys. 97, 1819-1832.

Meister, I., Krings, T., Foltys, H., Boroojerdi, B., Mueller, M., Toepper, R., Thron, A., 2005 Effects of long-term practice and task complexity in musicians and nonmusicians performing simple and complex motor tasks: implications for cortical motor organization. Hum. Brain Mapp. 25, 345-352.

Miyachi, S., Hikosaka, O., Miyashita, K., Karadi, Z., Rand, M., 1997. Differential roles of monkey striatum in learning of sequential hand movement. Exp. Brain Res. 115, 1-5.

Miyachi, S., Hikosaka, O., Lu, X., 2002. Differential activation of monkey striatal neurons in the early and late stages of procedural learning. Exp. Brain Res. 146, 122-126.

Mukai, I., Kim, D., Fukunaga, M., Japee, S., Marrett, S., Ungerleider, L.G., 2007. Activations in visual and attention-related areas predict and correlate with the degree of perceptual learning. J. Neurosci. 27, 11401-11411.

Mushiake, H., Saito, N., Sakamoto, K., Itoyama, Y., Tanji, J., 2006. Activity in the lateral prefrontal cortex reflects multiple steps of future events in action plans. Neuron 50 , 631-641.

Nissen, M.J., Bullemer, P., 1987. Attentional requirements of learning: evidence from performance measures. Cogn. Psychol. 19, 1-32.

Oldfield, R.C., 1971. The assessment and analysis of handedness: the Edinburgh Inventory. Neuropsychologia 9, 97-113.

Pascual-Leone, A., Amedi, A., Fregni, F., Merabet, L.B., 2005. The plastic human brain cortex. Ann. Rev. Neurosci. 28, 377-401.

Poldrack, R.A., 2000. Imaging brain plasticity: conceptual and methodological issues - a theoretical review. Neuroimage 12, 1-13.

Poldrack, R.A., Sabb, F.W., Foerde, K., Tom, S.M., Asarnow, R.F., Bookheimer, S.Y., Knowlton, B.J., 2005. The neural correlates of motor skill automaticity.J. Neurosci. 25, 5356-5364.

Quian Quiroga, R., Snyder, L.H., Batista, A.P., Cui, H., Andersen, R.A., 2006. Movement intention is better predicted than attention in the posterior parietal cortex. J. Neurosci. 26, 3615-3620.

Reithler, J., Reithler, H., van den Boogert, E., Goebel, R., van Mier, H., 2006. Resistancebased high resolution recording of predefined 2-dimensional pen trajectories in an fMRI setting. J. Neurosci. Meth. 152, 10-17.

Reithler, J., van Mier, H.I., Peters, J.C., Goebel, R., 2007. Nonvisual motor learning influences abstract action observation. Curr. Biol. 17, 1201-1207.

Riecker, A., Wildgruber, D., Mathiak, K., Grodd, W., Ackermann, H., 2003. Parametric analysis of rate-dependent hemodynamic response functions of cortical and subcortical brain structures during auditorily cued finger tapping: a fMRI study. Neuroimage 18, 731-739.

Rizzolatti, G., Luppino, G., 2001. The cortical motor system. Neuron 31, 889-901.
Rizzolatti, G., Luppino, G., Matelli, M., 1998. The organization of the cortical motor system: new concepts. Electroencephalogr. Clin. Neurophysiol. 106, 283-296.

Robertson, E.M., Tormos, J.M., Maeda, F., Pascual-Leone, A., 2001. The role of the dorsolateral prefrontal cortex during sequence learning is specific for spatial information. Cereb. Cortex 11, 628-635.

Rozzi, S., Calzavara, R., Belmalih, A., Borra, E., Gregoriou, G.G., Matelli, M., Luppino, G. 2006. Cortical connections of the inferior parietal cortical convexity of the macaque monkey. Cereb. Cortex 16, 1389-1417.

Saito, N., Mushiake, H., Sakamoto, K., Itoyama, Y., Tanji, J., 2005. Representation of immediate and final behavioral goals in the monkey prefrontal cortex during an instructed delay period. Cereb. Cortex 15, 1535-1546.

Sanes, J.N., 2003. Neocortical mechanisms in motor learning. Curr. Opin. Neurobiol. 13 225-231.

Snyder, L.H., Batista, A.P., Andersen, R.A., 1998. Change in motor plan, without a change in the spatial locus of attention, modulates activity in posterior parietal cortex. J. Neurophysiol. 79, 2814-2819.

Talairach, J., Tournoux, P., 1988. Co-planar Stereotaxic Atlas of the Human Brain. G. Thieme, Stuttgart.

Tanji, J., 2001. Sequential organization of multiple movements: involvement of cortical motor areas. Annu. Rev. Neurosci. 24, 631-651.

Toni, I., Krams, M., Turner, R., Passingham, R.E., 1998. The time course of changes during motor sequence learning: a whole-brain fMRI study. Neuroimage 8, 50-61.

Turner, R.S., Grafton, S.T., Votaw, J.R., Delong, M.R., Hoffman, J.M., 1998. Motor subcircuits mediating the control of movement velocity: a PET study. J. Neurophysiol. 80, 2162-2176.

van Mier, H., 2000. Human learning. In: Toga, A.W., Mazziotta, J.C. (Eds.), Brain Mapping: the Systems. Academic Press, San Diego, pp. 605-617.

van Mier, H., Hulstijn, W., Petersen, S.E., 1993. Changes in motor planning during the acquisition of movement patterns in a continuous task. Acta Psychol. 82, 291-312.

van Mier, H., Tempel, L.W., Perlmutter, J.S., Raichle, M.E., Petersen, S.E., 1998. Changes in brain activity during motor learning measured with PET: effects of hand of performance and practice. J. Neurophysiol. 80, 2177-2199.

Vaughan, J.T., Garwood, M., Collins, C.M., Liu, W., DelaBarre, L., Adrainy, G., Andersen, P., Merkle, H., Goebel, R., Smith, M.B., Ugurbil, K., 2001. 7 T vs. 4 T: RF power, homogeneity, and signal-to-noise comparison in head images. Magn. Reson. Med 46, 24-30.

Wise, S.P., Boussaoud, D., Johnson, P.B., Caminiti, R., 1997. Premotor and parietal cortex: corticocortical connectivity and combinatorial computations. Annu. Rev. Neurosci 20, 25-42.

Wu, T., Kansaku, K., Hallett, M., 2004. How self-initiated memorized movements become automatic: a functional MRI study. J. Neurophysiol. 91, 1690-1698.

Xiong, J., Liangsuo, M., Wang, B., Narayana, S., Duff, E.P., Egan, G.F., Fox, P.T., 2009. Longterm motor training induced changes in regional cerebral blood flow in both task and resting states. Neuroimage $45,75-82$. 